\title{
Thorium isotopes in the Southeast Atlantic Ocean: Tracking scavenging during water mass mixing along neutral density surfaces
}

\author{
Roy-Barman Matthieu ${ }^{1,}{ }^{*}$, Thil François ${ }^{1}$, Bordier Louise ${ }^{1}$, Dapoigny Arnaud ${ }^{1}$, Foliot Lorna ${ }^{1}$, \\ Ayrault Sophie ${ }^{1}$, Lacan François ${ }^{2}$, Jeandel Catherine ${ }^{2}$, Pradoux Catherine ${ }^{2}$, Garcia-Solsona Ester 2, 3 \\ ${ }^{1}$ Laboratoire des Sciences du Climat et de l'Environnement, LSCE-IPSL (CEA CNRS UVSQ), \\ Université Paris-Saclay, Orme des Merisiers - centre de Saclay, 91191, Gif-sur-Yvette, France \\ 2 LEGOS (CNRS/CNES/IRD/Université de Toulouse), Observatoire Midi-Pyrénées, 31400, Toulouse, \\ France \\ ${ }^{3}$ Dinàmica de la Terra i de l'Oceà, Facultat de Ciències de la Terra, Universitat de Barcelona, 08028, \\ Barcelona, Spain
}

*Corresponding author : Matthieu Roy-Barman, email address : matthieu.roy-barman@lsce.ipsl.fr

\begin{abstract}
:
The distributions of dissolved and particulate thorium isotopes (230Th and 232Th) were established in samples from the BONUS GoodHope (BGH) IPY-GEOTRACES cruise in the SE Atlantic sector of the Southern Ocean $\left(36^{\circ} \mathrm{S}-13^{\circ} \mathrm{E}\right.$ to $57^{\circ} \mathrm{S}-0^{\circ}$, Feb.-Mar. 2008). The distribution of total (dissolved + particulate) $232 \mathrm{Th}$ is dominated by the inputs from continental margins. The non-linear profiles of dissolved 230Th are interpreted as due to the southward upwelling of the isopycnal surfaces. However, total 230Th and 232Th versus salinity plots illustrate departures from binary mixing and provides evidence for non-conservative behavior of both isotopes along the section. We propose a model for total 230Th and 232Th scavenging and mixing along isopycnal surfaces. We use this model to estimate particle settling speeds and isopycnal eddy diffusion coefficients along the BGH section. Data-model comparison suggests particle settling velocities in the range of $400-700 \mathrm{~m} / \mathrm{y}$ and isopycnal eddy diffusivity of the order of $2000 \mathrm{~m} 2 / \mathrm{s}$.
\end{abstract}

\section{Highlights}

- Small deviations of thorium isotopes from a conservative behavior occurs during isopycnal mixing through the ACC. An advection-diffusion-scavenging model along neutral density surface is applied to thorium isotopes. Combining thorium isotopes allows constraining particle settling speeds and isopycnal mixing coefficients. 
Keywords : Thorium isotopes, Southern ocean, Atlantic, Marine particles, Isopycnal mixing 
1. Introduction

Thorium isotopes are recognized tracers of particle dynamics in the ocean that provide key information on ocean biogeochemical cycles (Bacon and Anderson, 1982, Nozaki et al., 1981, Roy-Barman et al., 1996). In particular, ${ }^{230} \mathrm{Th}$ is produced in situ by radioactive decay of ${ }^{234} \mathrm{U}$ and rapidly scavenged on marine particles, thus providing a chronometer for estimating the settling speed for marine particles. ${ }^{232} \mathrm{Th}$ is introduced in the ocean by continental inputs and hence can bring complementary information on marine particles compared to ${ }^{230} \mathrm{Th}$ (Roy-Barman et al., 2002).

In early studies, particle settling speeds were derived from ${ }^{230} \mathrm{Th}$ with a simple $1 \mathrm{D}$ (vertical) production-scavenging model, which was well adapted to oceanic areas with weak currents (Bacon and Anderson, 1982, Nozaki et al., 1981, Roy-Barman et al., 1996, RoyBarman, 2009). However, it is now clear that strong currents characterizing oceanic regions such as the Southern Ocean may significantly affect the distribution of ${ }^{230} \mathrm{Th}$ in the water column and hence potentially bias the estimate of the settling speed of marine particles obtained by the simple production-scavenging model. Therefore, a simple productionscavenging-advection model was proposed to constrain simultaneously the renewal rate of the deep waters and the settling speed of marine particles in the Atlantic sector of the Southern Ocean (Rutgers van der Loeff et al., 1996). However, it relies on rather crude approximations, such as uniform values for ventilation rate and particle settling speed over the whole water column. Another limitation of this model is that it does not consider the mixing of water masses with different origins and Th contents.

In the real ocean, the distribution of geochemical tracers depends on both nonconservative processes and mixing of water masses of different origins, in addition to advection by currents. This mixing is thought to occur preferentially along surfaces of constant density called isopycnal surfaces. Chase et al. (2003) suggested that the small gradients in ${ }^{230} \mathrm{Th}$ concentration observed along neutral density surfaces in the deep waters of the Southern Ocean argue for small eddy diffusive fluxes and little scavenging of ${ }^{230} \mathrm{Th}$ across the Antarctic Polar Front (APF). However, they also advocated for further work to better constrain both nuclide concentrations along isopycnal surfaces and diffusion coefficients in the Southern Ocean.

In the present work, we take advantage of high precision ${ }^{230}$ Th data collected during the Bonus GoodHope cruise to revisit the behavior of ${ }^{230}$ Th across the Southern Ocean and to try to unravel the respective roles of water mass mixing and particle scavenging along neutral 
density surfaces. Our goal is to explore if Th data can help constraining both particle settling speeds and water mixing rates using a model that is more complete than with the simple mixing-scavenging model.

\section{Sampling and methods}

\subsection{Hydrographic settings}

The oceanographic structure determined from the Bonus GoodHope (BGH) expedition has already been described (Chever et al., 2010, Bown et al., 2011, Garcia-Solsona et al., 2014, Abadie et al., 2017), so we only summarize the main features and focus on the 5 super stations (S1-S5 stations, Fig. 1) sampled for Th isotopes. Three main hydrological and circulation regimes characterize the studied area: the Subtropical domain (Station S1), the Antarctic Circumpolar Current (ACC; S2 to S4) and the Weddell Sea Gyre (S5). The subtropical domain is bounded to the south by the subtropical front (STF), which was located around $41^{\circ} \mathrm{S}-42^{\circ} \mathrm{S}$, north of S2. The ACC domain, incorporating the Subantarctic Front (SAF; $\sim 45^{\circ} \mathrm{S}$ ) and the Polar Front (PF; $\sim 50^{\circ} \mathrm{S}$ ), is bounded to the south by the southern ACC boundary (Sby). From the Sby to the Antarctic continent, water circulation is dominated by the cyclonic Weddell Gyre (WG; S5).

The subtropical regime is influenced from 0 down to $\sim 800 \mathrm{~m}$ by surface and intermediate waters of Indian Ocean origin $\left(\theta \geq 10^{\circ} \mathrm{C}, \mathrm{S} \geq 34.5\right)$, conveyed south of Africa by the Agulhas Current and detached eddies (Gladyshev et al., 2008). At intermediate depths ( 300-900 m), Antarctic Intermediate Water (AAIW) originates from cooled surface waters of the ACC that are subsequently subducted northward at the PF. Two varieties of AAIW have been recognized from $\mathrm{BGH}$ cruise data: one originating from the Indian Ocean (iAAIW) close to the African continent ( $>$ > 34.3; S1) and one formed in the Atlantic Ocean (aAAIW; S < 34.3; S2-S4). The Upper Circumpolar Deep Water (UCDW; ranging from 500 to $2000 \mathrm{~m}$ depth) is identified below the AAIW and upwells southwards. Below UCDW, the eastward flowing (and southward drifting) NADW is detected by its salinity maximum within the 2000-3000 m depth range. Two NADW branches are identified in the BONUS section: North of the Agulhas Ridge, higher salinities indicate advection by an eastern boundary 
current referred to as SE-NADW (S1 and S2 stations). South of the Agulhas Ridge, the main

134 (western) component of NADW (i.e., SW- NADW; S2-S4 stations) is incorporated into the ACC after flowing southward along the Argentine-Brazilian margin (Stramma and England, 1999). The other water mass encountered at southern ACC latitudes is high salinity Lower Circumpolar Deep Water (LCDW). Cold and fresher Antarctic Bottom Water (AABW) is also recognized, occupying the water column from LCDW/NADW depths down to the sea floor (Fig. 2). In the Weddell Sea Gyre domain (S5), we interpret deep oxygenated waters as due to input of recently ventilated AABW.

Water mass transport along the BGH section is mainly zonal. In the subtropical domain (station S1), it is dominated by the westward flowing Agulhas Current in the upper water column $(\mathrm{z}<1500 \mathrm{~m})$ and at depth by the eastward transport of SE-NADW as delineated

144 by Sokolov and Rintoul (2009). Stations S2, S3 and S4 are located within the Antarctic

145 Circumpolar Current, flowing eastward throughout the water column. Finally station S5 is 146 located in the Northern limb of the Weddell gyre, also flowing eastward. Therefore, the BGH 147 section is approximately perpendicular to the climatological mean (dominant) flows, so that 148 water masses should not flow directly from one BGH station to another. The different BGH stations would therefore not be directly connected by the mean flow. However, superimposed on this vigorous zonal circulation, slower meridional transports are clearly visible on meridional sections of water mass tracers such as salinity, temperature or nutrients, revealing notably the northward transport of AAIW and AABW, and southward transport of NADW

153 (Abadie et al., 2017). This meridional transport is presumably a residual circulation in which 154 lateral eddy fluxes largely balance the wind-driven circulation (Marshall and Speer, 2016). 155 While the circulation in the BGH area is therefore clearly 3D and dominated by zonal flows (preventing a direct link by mean advection between our 5 stations), some of the BGH samples can still reflect the effect of these meridional transports of these water masses upstream of the BGH section. In the following, transport models will be used to link tracer properties measured along the BGH section. We do not assume that the transports actually act along the BGH section (pure meridional transport is not realistic). However, we use the tracer properties measured along the $\mathrm{BGH}$ section to elucidate and quantify the meridional component (advection, diffusion) embedded within a dominant zonal component and therefore acts upstream of the BGH section, for instance between the Drake Passage and the BGH section. 


\subsection{Sampling}

The BONUS GoodHope cruise took place in the framework of the international polar year (IPY) from February $8^{\text {th }} 2008$ till March $17^{\text {th }} 2008$ on board the Research Vessel MarionDufresne II, from $34^{\circ} \mathrm{S} 18^{\circ} \mathrm{E}$ to $51^{\circ} \mathrm{S} 00^{\circ} \mathrm{W}$ and from $51^{\circ} \mathrm{S}$ to $58^{\circ} \mathrm{S}$ along the Greenwich meridian. The expedition took place during the late austral summer, when biological activity is high and ice cover is reduced. Five depth profiles (S1-S5 stations) were sampled for both dissolved and particulate Th with 10 or 11 depths per profile with 1 duplicated sample at stations S3, S4 and S5 (Fig. 1). An intercalibration (hereafter referred to as 'intercal') station was analyzed for 3 depths which were all duplicated.

Seawater samples were collected using Niskin bottles equipped with Teflon coated strings and mounted on a rosette frame with a CTD sensor. Challenger Oceanic in situ pumps (ISP) were used to filter large seawater volumes through SUPOR filters (pore size: $0.45 \mu \mathrm{m}$, filter diameter: $293 \mathrm{~mm}$ ). Typically, volumes ranging from $200 \mathrm{~L}$ to $1000 \mathrm{~L}$ were filtered.

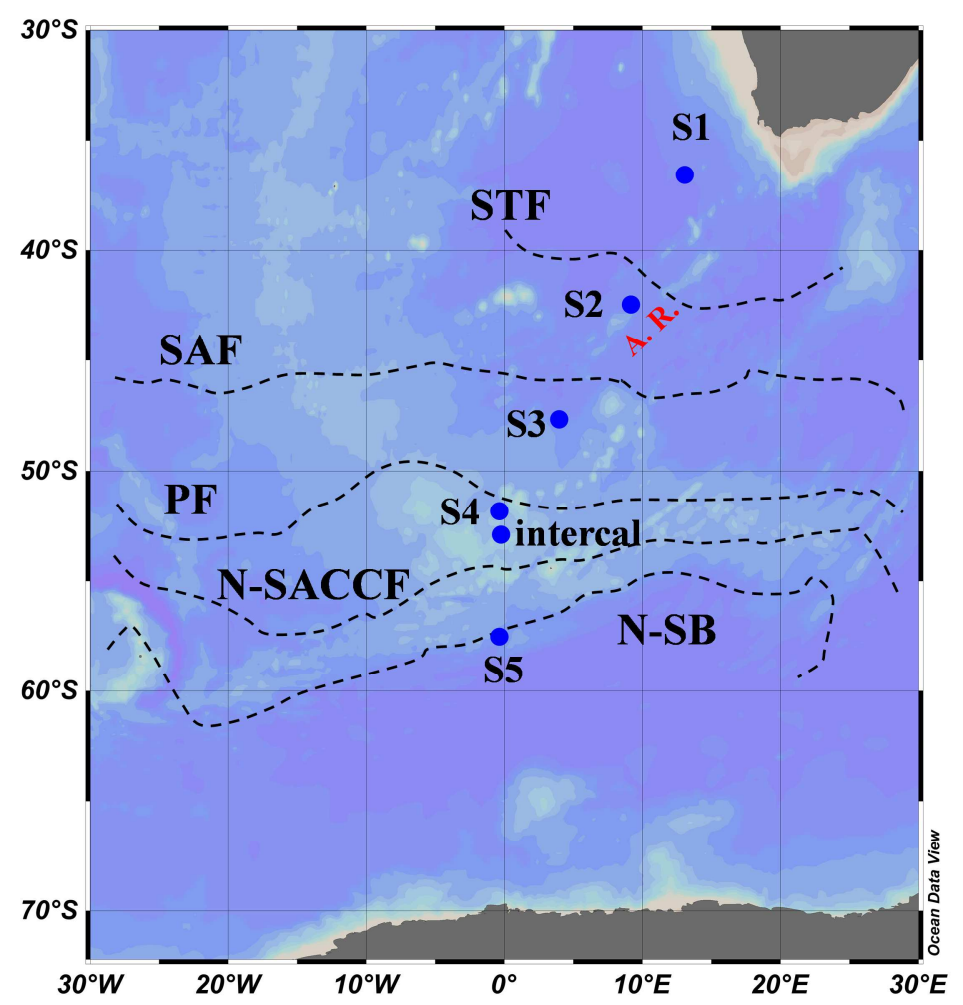

Fig. 1. Sampling stations during the BONUS-GoodHope section and main fronts (following Sokolov and Rintoul, 2009; mean path position): STF = SubTropical Front; SAF = SubAntarctic Front (middle branch); PF = Polar Front (middle branch); N-SACCF = northern branch of the Southern ACC front; N-SB = northern branch of the Southern Boundary. A.R.: Aghulas Ridge. 


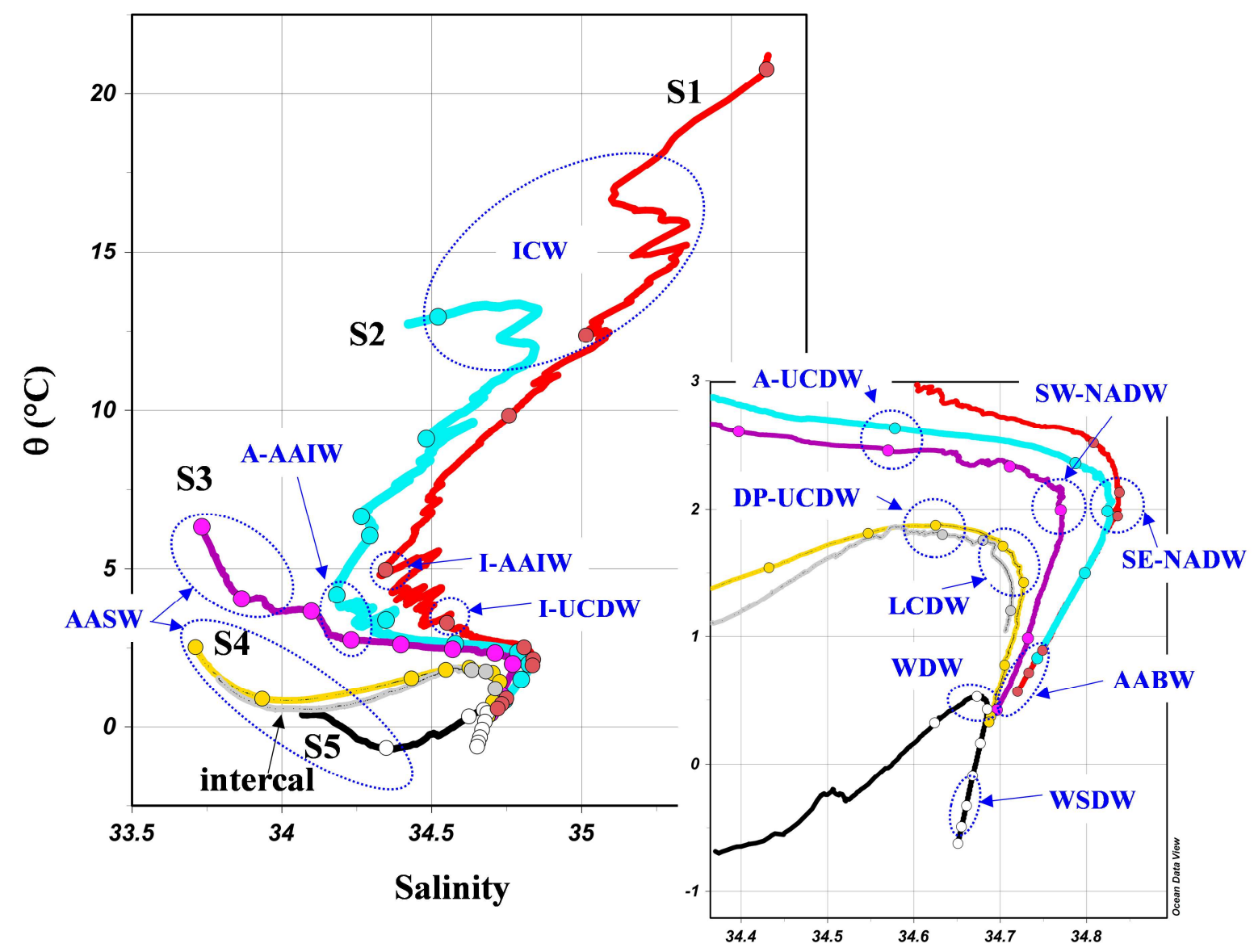

189 Fig.2: Potential temperature-salinity data during BGH. (a): full depth profiles. (b): deep waters. Dots: data at the depth of dissolved Th samples. Acronyms: AABW, Antarctic Bottom Water; AASW, Antarctic Surface Water; I-AAIW and A-AAIW, Antarctic Intermediate Water of Indian and Atlantic origins; I-CW, Indian Central Water; I-UCDW, A-UCDW, and DPUCDW, Indian, Atlantic, and Drake Passage Upper Circumpolar Deep Water; LCDW, Lower Circumpolar Deep Water; SE-NADW and SW-NADW, Southeast and Southwest North Atlantic Deep Water; WDW, Warm Deep Water; WSDW, Weddell Sea Bottom Water; WW, Winter Water.

\subsection{Analytical procedure}

Filtered seawater

Twenty liters of filtered seawater (Nuclepore, $90 \mathrm{~mm}$ diameter, $0.4 \mu \mathrm{m}$ pore size) were acidified, spiked with ${ }^{229} \mathrm{Th}$ and pre-concentrated on board using the ferric hydroxide coprecipitation technique as described in Piepgras et al. (1979). The precipitate was then recovered on filters (Supor, $90 \mathrm{~mm}, 0.4 \mu \mathrm{m}$ ), which were kept in petri dishes and stored in the dark. Back in the laboratory, the filters were submerged in $40 \mathrm{~mL}$ of $6 \mathrm{M} \mathrm{HCl}$ for $24 \mathrm{~h}$ in 300 $\mathrm{mL}$ Polytetrafluoroethylene beakers, enabling the dissolution of precipitate. The filters were 
then carefully rinsed with deionized water to recover all the dissolved precipitate. After evaporation, the residue was dissolved in $0.5 \mathrm{~mL} 7 \mathrm{M} \mathrm{HNO}_{3}$ and loaded on an anion-exchange column (AG1-X8 resin, 200-400 mesh) to separate the thorium fraction from the major elements, uranium and the rare earth elements (REE) (adapted from Jeandel et al., 2011). The total ${ }^{232}$ Th chemical blank is typically $48 \pm 14$ pg and represents generally less than $15 \%$ of

211 the sample although peaks with $50 \%$ of the sample occur for very ${ }^{232}$ Th-poor samples. Total

$212{ }^{230}$ Th chemical blank is typically $2.3 \pm 0.1 \mathrm{fg}$ and represents generally less than $5 \%$ of the 213 sample although peaks with $30 \%$ of the sample occur for very shallow samples.

\section{Particles collected from Niskin bottle filtrations}

From the twenty liter seawater samples used for dissolved Th analyses (described above), particulate samples were also available on the $90 \mathrm{~mm}$ diameter $0.4 \mu \mathrm{m}$ porosity

218 Nuclepore membranes used for filtration (hereafter referred to as Niskin filtration). 219 Membranes were transferred from their petri dishes to Teflon beaker containing $15 \mathrm{~mL} 6 \mathrm{M}$ $220 \mathrm{HCl}$ and $2.5 \mathrm{~mL} 15 \mathrm{M} \mathrm{HNO}_{3}$. They were heated 90 minutes at $130^{\circ} \mathrm{C}$. After leaving them cool, $0.5 \mathrm{~mL} 23 \mathrm{M}$ HF was added, and the mixture was heated again as previously. The membranes were removed from the leaching solutions and rinsed over the beakers with milliQ water. After evaporation, the samples were dissolved in $3 \mathrm{~mL} 0.32 \mathrm{M} \mathrm{HNO}_{3}$ for analysis by Quadrupole Induced Coupled Plasma Mass Spectrometry.

\section{Particles collected from in situ pump filtrations}

Filters from the in situ pumps were cut into pieces using ceramic scissors. Several leaching steps were necessary to recover Th without attacking the filters. Filter pieces were

231 first leached with $200 \mathrm{~mL}$ of $6 \mathrm{~N} \mathrm{HCl}$ and $1.5 \mathrm{~mL}$ of $24-25 \mathrm{~N} \mathrm{HF}$ in a $300 \mathrm{~mL}$ Teflon beaker

232 for 2 days at $75^{\circ} \mathrm{C}$. The filter pieces were removed from the leaching solution and rinsed with 233 a MQ water squeeze bottle over the leaching beaker. The filter pieces were saved apart. The 234 leaching and rinsing solutions were evaporated down to $\sim 10 \mathrm{~mL}$ and transferred into a $30 \mathrm{~mL}$ 235 Teflon beaker. Then, the filter pieces were leached a second time with $150 \mathrm{~mL}$ of $7 \mathrm{~N} \mathrm{HNO}_{3}$ and $0.05 \mathrm{~mL}$ of $29 \mathrm{~N} \mathrm{HF}$ for 2 days at $75^{\circ} \mathrm{C}$. The filter pieces were removed from the leaching solution and rinsed with MQ water that was again recovered into the leaching beaker. After

238 evaporation to a few $\mathrm{mL}$, this solution was added to the first leaching/rinsing solution. The $300 \mathrm{~mL}$ Teflon beaker was rinsed in warm diluted $\mathrm{HNO}_{3}$ to remove any particle sticking on 
the beaker walls and the resulting solution was also added to the $30 \mathrm{~mL}$ beaker. The resulting solution was then spiked with ${ }^{229} \mathrm{Th}$ (and ${ }^{233} \mathrm{~Pa}$ ), dried and dissolved again in a solution with 4 $\mathrm{mL}$ of $14 \mathrm{~N} \mathrm{HNO}_{3}$ and $1 \mathrm{~mL}$ of $12 \mathrm{~N} \mathrm{HCl}$. After 1 night on a hot plate, the solution was dried and the residue was dissolved again in $10 \mathrm{ml}$ of $1 \mathrm{~N} \mathrm{HNO}_{3}$. Since filters were not rinsed immediately after filtration with distilled water on board, it was preferable to remove the salt before the column chemistry. Therefore, $40 \mu \mathrm{L}$ of a Fe solution $(60 \mathrm{mg} / \mathrm{g})$ were added. After 1h-heating, Fe was precipitated by raising the $\mathrm{pH}$ to about 8 with $\mathrm{NH}_{3}$. The Fe precipitate (that coprecipitates Th isotopes) was separated by centrifugation and rinsed several times. Finally, it was dissolved in $0.25 \mathrm{ml}$ of $8 \mathrm{~N} \mathrm{HNO}_{3}$, ready for loading on an anionic column. Th isotopes were separated from $\mathrm{Fe}$ by ion exchange chromatography on a small volume $(0.5 \mathrm{ml})$ column of AG1X8 resin (200-400 mesh) with a procedure adapted from Jeandel et al., 2011 (Gdaniec et al., 2018).

The total ${ }^{232}$ Th chemical blank was typically $42 \pm 25 \mathrm{pg}$, although few blanks as high as $1400 \mathrm{pg}$ were observed. Given the good agreement between the particulate ${ }^{232} \mathrm{Th}$ concentrations obtained with the Niskin filtrations (see Fig. ES1) and the ISP ${ }^{232} \mathrm{Th}$ concentrations corrected with the low blank values, the highest blanks were not taken into account to correct the ISP data. Total ${ }^{230} \mathrm{Th}$ chemical blank was typically $1 \pm 1 \mathrm{fg}$. As for ${ }^{232} \mathrm{Th}$, a small number of very large blanks (up to $125 \mathrm{fg}$ ) were obtained but assumed to be outliers.

Mass spectrometry

For dissolved and in situ pump samples, Th isotopes were measured on a MC-ICPMS Neptune + (Thermo-Fischer). The dissolved samples were analyzed with the initial configuration of the Neptune + with an Apex desolvator. The particulate samples were analyzed after the Neptune's upgrade with a Jet interface and an Aridus 2 desolvating nebulizer. The acquisition conditions are given in Gdaniec et al. (2018). The accuracy of the MC-ICPMS measurement was checked by analysis of Th standard IRMM035 $\left({ }^{230} \mathrm{Th} /{ }^{232} \mathrm{Th}=\right.$ $\left.(11.31 \pm 0.12) \times 10^{-6}, \mathrm{n}=6\right)$ and IRMM036 $\left.(3.059 \pm 0.033) \times 10^{-6}, \mathrm{n}=8\right)$, in good agreement with reference values: ${ }^{230} \mathrm{Th} /{ }^{232} \mathrm{Th}=(11.38 \pm 0.10) \times 10^{-6}$ for IRMM035 and ${ }^{230} \mathrm{Th} /{ }^{232} \mathrm{Th}=$ $(3.047 \pm 0.024) \times 10^{-6}$ for IRMM036 (Sims et al., 2008). The quality of the analyses was checked through the GEOTRACES intercalibration exercise where we obtained precise and accurate dissolved Th concentrations well within the consensus values (Anderson et al., 2012). 
For Niskin filtration samples, ${ }^{232}$ Th was analyzed by quadrupolar ICPMS (Agilent

276 7500CE of the Observatoire Midi Pyrénées, Toulouse). Indium and rhenium (100 ppt, added

277 to the samples) were used as internal standards to monitor instrument sensitivity variations.

278 Reproducibility calculated from 3 duplicated samples (2 different Niskins) was on average

$27912 \%$ (2 standard deviations). Detection limit was $0.5 \mathrm{pg} / \mathrm{kg}$.

280

281

282

283 3. Results

284 3.1. Dissolved thorium

285

286 Dissolved ${ }^{232} \mathrm{Th}$ concentrations $\left({ }^{232} \mathrm{Th}_{\mathrm{d}}\right.$ ) range from $4.7 \mathrm{pg} / \mathrm{kg}$ to $288 \mathrm{pg} / \mathrm{kg}$ (Fig. 2a, Tab. ES

287 1) and generally increase with depth. At stations $S 1$ and $S 2$, the ${ }^{232} \mathrm{Th}_{\mathrm{d}}$ profiles have a local 288 maximum around 200-400 $\mathrm{m}$ depth and a sharp increase at bottom depths. Conversely, at 289 station $\mathrm{S} 3,{ }^{232} \mathrm{Th}_{\mathrm{d}}$ for the deepest sample is relatively low. This feature was also noted for 290 dissolved REE (Garcia-Solsona et al. 2014) and for ${ }^{230} \mathrm{Th}_{\mathrm{d}}$ (see below) analyzed on the same 291 water sample. Along the section, the lowest ${ }^{232} \mathrm{Th}_{\mathrm{d}}$ are found at station S3 and S4, far from the 292 coasts of Africa and Antarctica $\left({ }^{232} \mathrm{Th}_{\mathrm{d}}=4.7-30 \mathrm{pg} / \mathrm{kg}\right)$. All the ${ }^{232} \mathrm{Th}_{\mathrm{d}}$ duplicates agree within 293 analytical uncertainties. 
${ }^{232} \mathrm{Th}_{\mathrm{d}}(\mathrm{pg} / \mathrm{kg})$

(a)

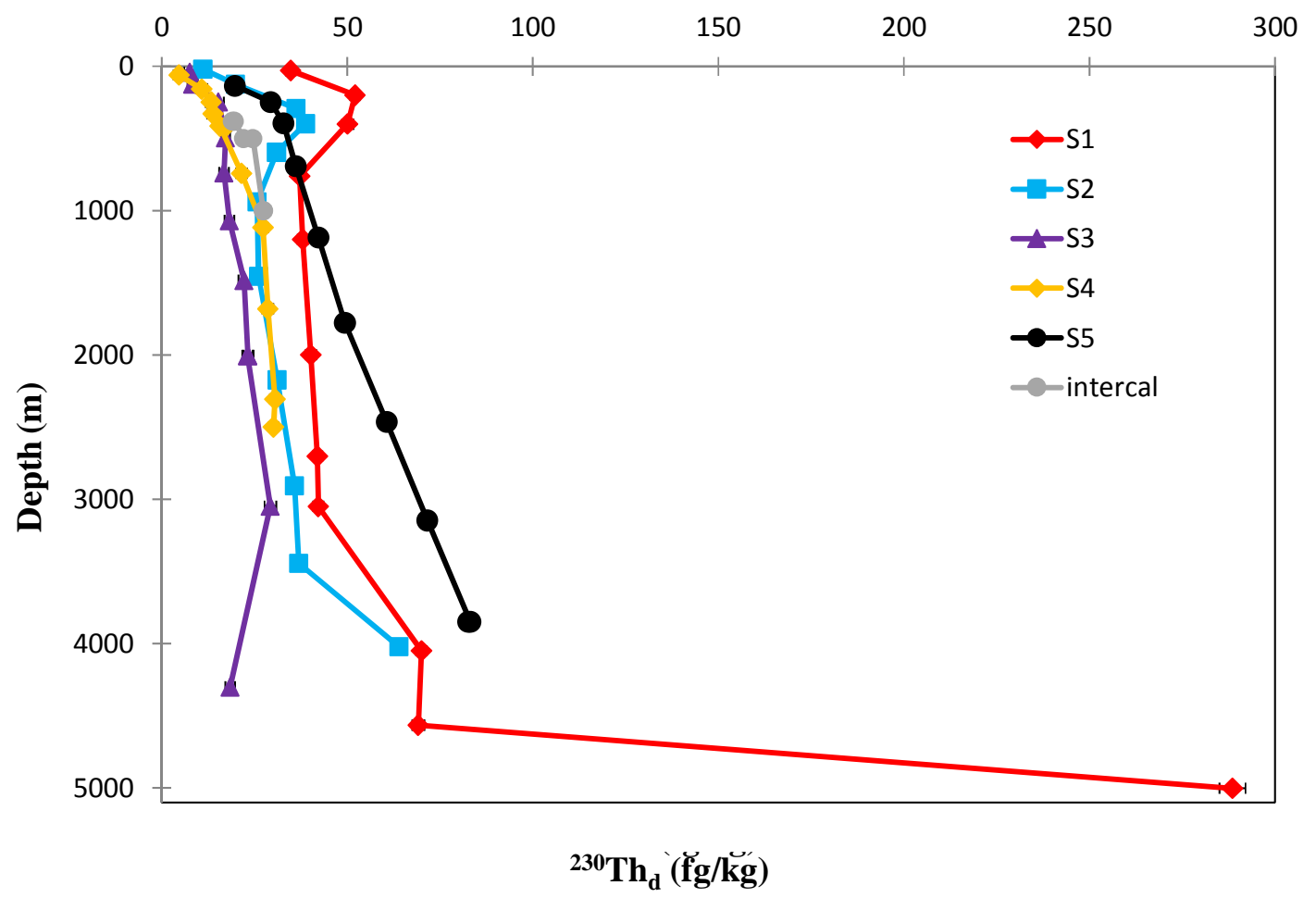

(b)

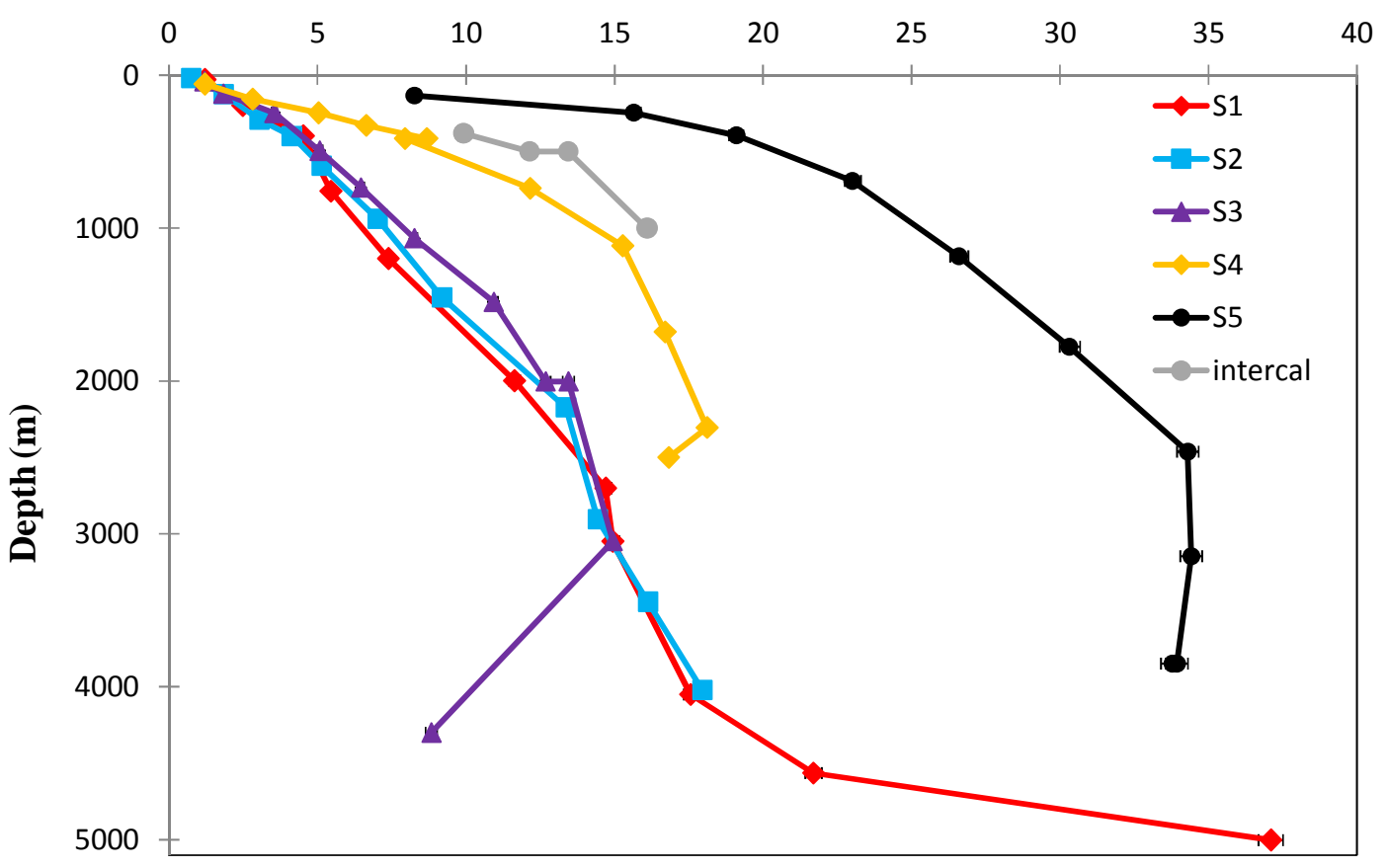


304 Dissolved ${ }^{230} \mathrm{Th}$ concentrations $\left({ }^{230} \mathrm{Th}_{\mathrm{d}}\right)$ range from $0.7 \mathrm{fg} / \mathrm{kg}$ to $37 \mathrm{fg} / \mathrm{kg}$ (Fig. 3b) and 305 generally increase with depth. At stations $\mathrm{S} 1$ and $\mathrm{S} 2$, the ${ }^{230} \mathrm{Th}_{\mathrm{d}}$ profiles increase 306 approximately linearly from the surface down to $4000 \mathrm{~m}$ depth. At station S1, there is a sharp 307 increase of ${ }^{230} \mathrm{Th}_{\mathrm{d}}$ above the seafloor. Conversely, at station S3, S4 and S5, the ${ }^{230} \mathrm{Th}_{\mathrm{d}}$ profiles 308 have concave shapes and, for a given depth, ${ }^{230} \mathrm{Th}_{\mathrm{d}}$ is higher at stations S4 and S5 than at S1, $309 \mathrm{~S} 2$ and $\mathrm{S} 3$. All ${ }^{230} \mathrm{Th}_{\mathrm{d}}$ duplicates agree within $9 \%$ (3 of them agreeing within the analytical 310 uncertainties).

311 Following GEOTRACES good practices, a comparison with 2 stations of the Zero-Drake 312 cruise (Rutgers van de Loeff et al., 2016) is provided (Fig. ES3). Profiles agree within 313 uncertainties for ${ }^{230} \mathrm{Th}$ and more qualitatively for ${ }^{232} \mathrm{Th}$.

\subsection{Particulate thorium}

317 Particulate ${ }^{232} \mathrm{Th}$ concentrations $\left({ }^{232} \mathrm{Th}_{\mathrm{p}}\right)$ have been already reported elsewhere (Garcia318 Solsona et al., 2014). ${ }^{232} \mathrm{Th}_{\mathrm{p}}$ from ISP filtrations range from $0.08 \mathrm{pg} / \mathrm{kg}$ to $371 \mathrm{pg} / \mathrm{kg}$ (Fig. $4 \mathrm{a}$, 319 Tab. ES2). There is generally a good agreement between ${ }^{232} \mathrm{Th}_{\mathrm{p}}$ profiles obtained with in situ 320 pumps and profiles obtained with Niskin filtrations. The most notable exception is above the 321 seafloor at station $\mathrm{S} 3$, where Niskin bottle filtration gives ${ }^{232} \mathrm{Th}_{\mathrm{p}}=27 \mathrm{pg} / \mathrm{kg}$, whereas ISP 322 filtration gives ${ }^{232} \mathrm{Th}_{\mathrm{p}}=2.5 \mathrm{pg} / \mathrm{kg}$. Apart from this particular feature recorded at $\mathrm{S} 3$, the ${ }^{232} \mathrm{Th}_{\mathrm{p}}$ 323 profiles generally increase with depth with a sharp increase above the seafloor. Along the 324 section, the highest ${ }^{232} \mathrm{Th}_{\mathrm{p}}$ concentrations are found at station $\mathrm{S} 1$ and $\mathrm{S} 2$, which are the 325 stations closest to the African coast.

326 All the ${ }^{232} \mathrm{Th}_{\mathrm{p}}$ duplicates agree within analytical uncertainties. The variation in ${ }^{232} \mathrm{Th}_{\mathrm{p}}$ 327 observed between in situ pumps and Niskin filtrations (Fig. ES1) is of the same order than 328 observed for other insoluble elements (Planquette and Sherrell, 2012).

331 Particulate ${ }^{230} \mathrm{Th}$ concentrations $\left({ }^{230} \mathrm{Th}_{\mathrm{p}}\right.$ ) range from $0.02 \mathrm{fg} / \mathrm{kg}$ to $28 \mathrm{fg} / \mathrm{kg}$ (Fig. $\left.4 \mathrm{~b}\right) .{ }^{230} \mathrm{Th}_{\mathrm{p}}$ 332 generally increase with depth. At stations $\mathrm{S} 1$ and $\mathrm{S} 2$, the ${ }^{230} \mathrm{Th}_{\mathrm{p}}$ profiles increase 333 approximately linearly from the surface down to $4000 \mathrm{~m}$ depth and then present a sharp 334 increase of ${ }^{230} \mathrm{Th}_{\mathrm{p}}$ above the seafloor (height above the seafloor is $295 \mathrm{~m}$ and $212 \mathrm{~m}$ at, 
335 respectively, $\mathrm{S} 1$ and $\mathrm{S} 2$ ). At station $\mathrm{S} 3,{ }^{230} \mathrm{Th}_{\mathrm{p}}$ decreases just above the seafloor similarly to $336{ }^{232} \mathrm{Th}_{\mathrm{d}}$ (height above the seafloor is $218 \mathrm{~m}$ at $\mathrm{S} 3$ ).

337 Two in situ pump filtrations were replicated. At station S3 and 3050-m depth, the 338 replicates agree within $4 \%$ for both ${ }^{232} \mathrm{Th}_{\mathrm{p}}$ and ${ }^{230} \mathrm{Th}_{\mathrm{p}}$. At station $\mathrm{S} 4$ and 1130-m depth, both 339 the ${ }^{232} \mathrm{Th}_{\mathrm{p}}$ and ${ }^{230} \mathrm{Th}_{\mathrm{p}}$ concentrations differ by a factor of $\sim 2$, suggesting either a problem of 340 volume measurement, data recording or a loss of particles during the filter handling. We 341 choose to use the concentrations measured on the filter with the largest filtered volume of 342 water, because it corresponds to the ${ }^{232} \mathrm{Th}_{\mathrm{p}}$ concentration closest to the Niskin filtration. 343 
(a) ${ }^{232} \mathrm{Th}(\mathrm{pg} / \mathrm{kg})$

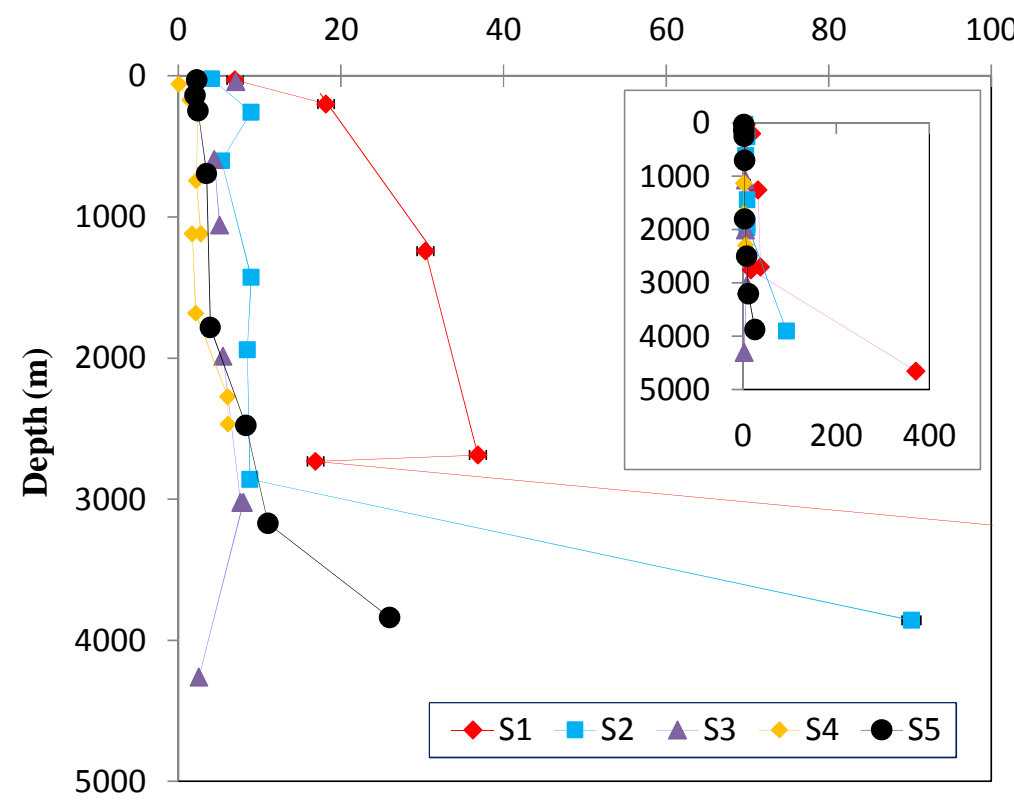

(b)
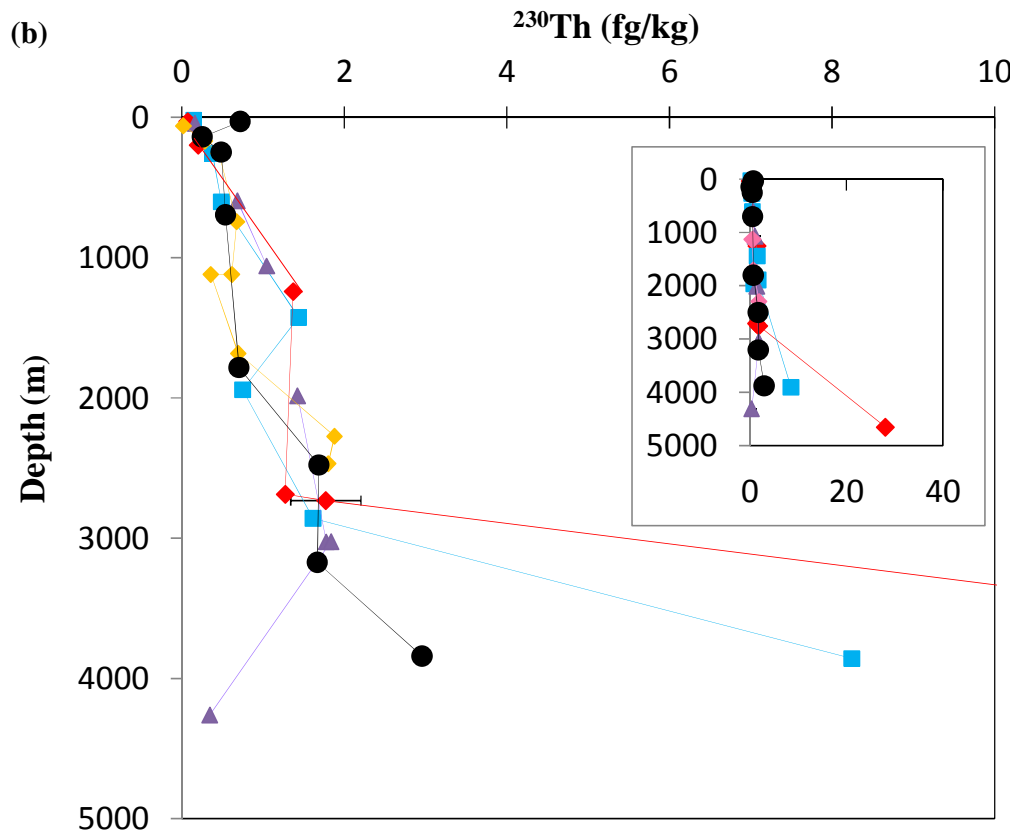

Fig. 4. Particulate Thorium profiles collected with in situ pumps. (a) Particulate ${ }^{232} \mathrm{Th}$.

(b) Particulate ${ }^{230} \mathrm{Th}$. Insets: expanded concentration scales to display particulate concentration maximum at $\mathrm{S} 1$.

4. Discussion

The dissolved ${ }^{230} \mathrm{Th}$ profiles obtained during Bonus GoodHope are consistent with

354 previous results from the South Atlantic and the Weddell Sea (Rutgers van der Loeff and 
Berger, 1993, Rutgers van der Loeff et al., 2016). Station S1 has a relatively linear profile from the surface down to $3000 \mathrm{~m}$ deep. This is consistent with the 1D reversible scavenging model, in which ${ }^{230} \mathrm{Th}$ is only transported vertically by reversible scavenging on settling particles. However, even though S1 is located in the subtropical gyre, north of the subtropical front, the profile is not perfectly linear. This presumably reflects the influence of surface and intermediate waters advected from the Indian Ocean (ICW and AAIW down to $1200 \mathrm{~m}$ ) and deep water advected from the Atlantic Ocean (SE-NADW). The ${ }^{230} \mathrm{Th}$ content of the surface and intermediate waters at S1 compare well with those reported in the south Indian Ocean $\left({ }^{230} \mathrm{Th} \approx 4-5 \mathrm{fg} / \mathrm{kg}\right.$ at $500 \mathrm{~m}$, Thomas et al., 2006). The ${ }^{230} \mathrm{Th}$ contents of deep waters $\left({ }^{230} \mathrm{Th} \approx\right.$ $13 \mathrm{fg} / \mathrm{kg}$ at $2000 \mathrm{~m}$ ) at $\mathrm{S} 1$ are on the low side of those reported for SE-NADW sampled off Namibia $\left({ }^{230} \mathrm{Th} \approx 12-24 \mathrm{fg} / \mathrm{kg}\right.$ at $2000 \mathrm{~m}$, Scholten et al. 2008) and that flows towards $\mathrm{S} 1$ (Arhan et al., 2003), suggesting the imprint of boundary scavenging. The deepest parts of the S1 profile significantly deviate from the linear increase: the higher dissolved and particulate ${ }^{230} \mathrm{Th}$ (as well as ${ }^{232} \mathrm{Th}$ ) concentrations suggest a release from the South African margin sediments.

From the surface down to $3000 \mathrm{~m}$ depth, the ${ }^{230} \mathrm{Th}$ profiles of $\mathrm{S} 2$ and $\mathrm{S} 3$ are similar to $\mathrm{S} 1$. In the deepest waters, S2 has a strong increase of its dissolved and particulate ${ }^{230} \mathrm{Th}$ (although less than S1) also suggesting inputs from the sediments or lateral transport from the African margin. By contrast, at S3, the low ${ }^{230} \mathrm{Th}_{\mathrm{d}}$ concentrations at a depth of $4500 \mathrm{~m}$ could also be attributed to bottom scavenging (a low REE content on the same sample was also noted by Garcia-Solsona et al., 2014).

The strongly concave shapes of the ${ }^{230} \mathrm{Th}_{\mathrm{d}}$ profiles at S4 and S5 strongly suggests these profiles are impacted by the upwelling of LCDW (Rutgers van der Loeff and Berger, 1993). The ${ }^{230} \mathrm{Th}_{\mathrm{d}}$ profile at S3 has also a concave shape that can be regarded as a result of the LCDW upwelling. However, above $3000 \mathrm{~m}$ depth, it is not so different from the S1 profile where no LCDW upwelling is suspected. Also, the low ${ }^{230} \mathrm{Th}_{\mathrm{d}}$ concentrations at a depth of $4500 \mathrm{~m}$, that accentuate the nonlinearity of the profile, could also be attributed to bottom scavenging.

At stations $\mathrm{S} 1, \mathrm{~S} 2$ and $\mathrm{S} 3$, the ${ }^{230} \mathrm{Th}_{\mathrm{p}}$ profiles have very similar slopes, particularly from the 386 surface down to $1500 \mathrm{~m}$ depth. We consider the conservation equation of the $1 \mathrm{D}$ reversible scavenging model at steady state (and neglecting ${ }^{230} \mathrm{Th}$ radioactive decay):

$$
\frac{\partial C_{t}}{\partial t}=P_{d}-w_{p} \frac{\partial C_{p}}{\partial z}=0
$$


388 Where $\mathrm{C}_{\mathrm{t}}$ is the total (dissolved + particulate) ${ }^{230}$ Th concentration, $\mathrm{P}_{\mathrm{d}}$ is the in situ production 389 rate of ${ }^{230} \mathrm{Th}\left(\mathrm{P}_{\mathrm{d}}=0.56 \mathrm{fg} / \mathrm{kg} / \mathrm{y}\right), \mathrm{w}_{\mathrm{p}}$ is the particle settling speed and $\mathrm{C}_{\mathrm{p}}$ the particulate ${ }^{230} \mathrm{Th}$ 390 concentration. Hence, $\mathrm{w}_{\mathrm{p}}$ is given by: $\mathrm{w}_{\mathrm{p}}=\mathrm{P} /\left(\partial^{230} \mathrm{Th}_{\mathrm{p}} / \partial \mathrm{z}\right)$. Using an average slope of 0.001 $391 \mathrm{fg} / \mathrm{kg} / \mathrm{m}$, we obtain that $\mathrm{w}_{\mathrm{p}}=560 \mathrm{~m} / \mathrm{d}$, in agreement with Rutgers van der Loeff and Berger 392 (1993).

In the southern part of the section, we first use the mixing-scavenging model introduced by Rutgers van der Loeff and Berger (1993) to evaluate the impact of lower Circumpolar Deep Water upwelling and input into the Weddell Gyre. This "scavengingmixing" model relies on several assumptions:

(i) The representation of mixing with a constant restoring term at all depths (eq. 3). This is largely ad hoc, so that the physical interpretation of $\mathrm{C}_{\mathrm{it}}$ and $\tau_{\mathrm{w}}$ is unclear.

401 (ii) the omission of the effects of vertical transport by advection and diffusion,

402 (iii) steady state,

403 (iv) the partition coefficient $\mathrm{K}$ is vertically uniform. It implies that the ${ }^{230} \mathrm{Th}_{\mathrm{xs}}$ particulate 404 fraction is constant over the depth profile. Clear variations of the ${ }^{230} \mathrm{Th}_{\mathrm{xs}}$ particulate fraction 405 (Tab. ES2) occur in the deepest samples either due to particle inputs from the margins 406 (stations S1, S2 and S5, see Gdaniec et al., 2019) or following hydrothermal scavenging 407 (station S3).

408 (v) $\mathrm{K}$ is very small compared to 1 , so that $\mathrm{C}_{\mathrm{d}}$ could be approximated by $\mathrm{C}_{\mathrm{t}}$. Apart for the 409 deepest samples at stations S1 and S2, it introduces an underestimation of $\mathrm{w}_{\mathrm{p}}$ by $13 \%$ at most.

410 (vi) the particle settling velocity $\mathrm{w}_{\mathrm{p}}$ is vertically uniform. This assumption is deduced the from 411 linear dissolved and particulate ${ }^{230}$ Th profiles observed in regions unaffected by strong deep 412 currents (Roy-Barman et al., 1996).

413 (vii) $\mathrm{C}_{\mathrm{d}}$ is negligible near the surface. 


$$
\frac{\partial C_{t}}{\partial t}=P_{d}+\frac{\left(C_{i_{-}-}-C_{t}\right)}{\tau_{w}}-w_{p} \frac{\partial C_{p}}{\partial z}=0
$$

418 Where $\tau_{\mathrm{w}}$ is restoring time scale taken equivalent to the water residence time and $\mathrm{C}_{\mathrm{i}_{-} \mathrm{t}}$ is the 419 total ${ }^{230} \mathrm{Th}$ concentration of the inflowing water. Introducing a partition coefficient between 420 dissolved and particulate $\mathrm{Th}, \mathrm{K}=\mathrm{C}_{\mathrm{p}} / \mathrm{C}_{\mathrm{d}}$ and integrating equation 3 vertically over the water 421 column, the ${ }^{230} \mathrm{Th}_{\mathrm{d}}$ concentration at any depth is given by:

$$
C_{d}=\left(C_{i_{-} t}+P_{d} \tau_{w}\right) \times\left(1-\exp \left(-\frac{z}{w_{p} K \tau_{s}}\right)\right)
$$

424 For station 5, we use the ${ }^{230} \mathrm{Th}_{\mathrm{i}}=24 \mathrm{fg} / \mathrm{kg}$ for the LCDW (Rutgers van der Loeff and Berger, 425 1993), $\mathrm{K}=0.04$ is the average ratio measured at this station. Then, we adjust $\mathrm{w}_{\mathrm{p}}=875 \mathrm{~m} / \mathrm{y}$ and $426 \tau_{\mathrm{w}}=20 \mathrm{y}$ to obtain a good agreement between the modelled curve and the data (Fig. 5). The 427 low $\tau_{\mathrm{w}}$ obtained here compared to $45 \mathrm{y}$ used by Rutgers van der Loeff and Berger (1993) 428 derives presumably from the relatively peripheral position of station S5 in the Weddell Sea. 429 We confirm that the scavenging residence time in the Weddell Sea $\left(\tau_{\mathrm{s}}=\mathrm{d} /\left(2 \mathrm{Kw} \mathrm{p}_{\mathrm{p}}\right)=55\right.$ y for a 430 water column of a depth of $\mathrm{d}=4000 \mathrm{~m})$ is larger than in the subtropical gyre $\left(\tau_{\mathrm{w}}=25 \mathrm{y}\right.$ for a 431 water column of a depth of $4000 \mathrm{~m}$ ). On the whole, the model explains why the ${ }^{230} \mathrm{Th}_{\mathrm{d}}$

432 concentrations are high and do not increase linearly with depth in the Weddell Gyre.

We apply the same model to station $\mathrm{S} 4$. Here ${ }^{230} \mathrm{Th}_{\mathrm{i}}$ is also adjusted to obtain a good data-model agreement. We note that 2 modeled curves based on relatively different sets of $\tau_{\mathrm{w}}$ and $\mathrm{w}_{\mathrm{p}}$ values (ACC high and ACC low, Fig. 5) agree with the S4 data. This illustrates a limit of this method to estimate particle settling velocities. 


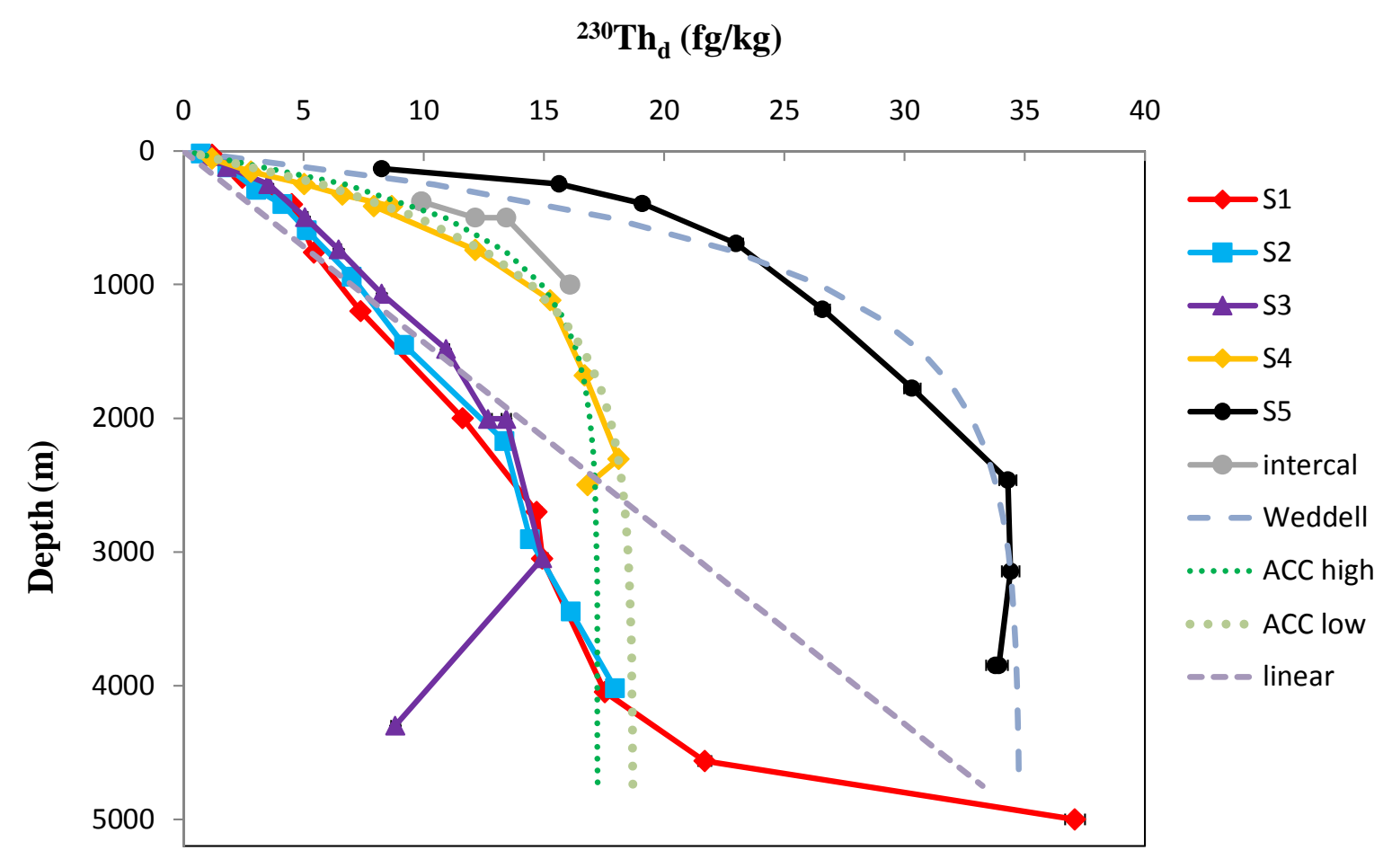

Fig. 5. Modelling of the Bonus Good Hope profiles. The dotted and dashed curves are calculated with Eq. 4. Weddell: $C_{i}=24 \mathrm{fg} / \mathrm{kg}, \mathrm{w}_{\mathrm{p}}=875 \mathrm{~m} / \mathrm{y}, \tau_{\mathrm{w}}=20 \mathrm{y}$ and $\mathrm{K}=0.04$. ACC low: $\mathrm{C}_{\mathrm{i}}=12 \mathrm{fg} / \mathrm{kg}, \mathrm{w}_{\mathrm{p}}=$ $803 \mathrm{~m} / \mathrm{y}, \tau_{\mathrm{w}}=12 \mathrm{y}$ and $\mathrm{K}=0.07$. ACC high: $\mathrm{C}_{\mathrm{i}}=15 \mathrm{fg} / \mathrm{kg}, \mathrm{w}_{\mathrm{p}}=1785 \mathrm{~m} / \mathrm{y}, \tau_{\mathrm{w}}=4 \mathrm{y}$ and $\mathrm{K}=0.125$. linear: $\mathrm{C}_{\mathrm{i}}=0 \mathrm{fg} / \mathrm{kg}, \mathrm{w}_{\mathrm{p}}=800 \mathrm{~m} / \mathrm{y}, \tau_{\mathrm{w}}=+\infty$ and $\mathrm{K}=0.1$.

This advection-scavenging model has been largely used to describe the vertical distribution of ${ }^{230} \mathrm{Th}$ in the Southern Ocean (Coppola et al., 2006, Venchiarutti et al., 2011, Rutgers van der Loeff et al., 2016). Despite crude assumptions (e.g., uniform influence throughout the water column by a single water mass), this mixing-scavenging model has the great merit of highlighting the impact of upwelling on ${ }^{230} \mathrm{Th}_{\mathrm{d}}$ profiles and to provide an estimate of the particle settling speed when the 1D production-scavenging model cannot be used. Nevertheless, this model cannot fully describe the upwelling and mixing of 2 different water masses along an isopycnal surface as observed during BGH and described in the next section. Salinity data help to illustrate this point. For a conservative tracer $\left(\mathrm{P}_{\mathrm{d}}=0, \mathrm{w}_{\mathrm{p}}=0\right.$ and $455 \mathrm{C}_{\mathrm{p}}=0$ ) and assuming steady state, equation (3) reduces to:

$456 \quad\left(S_{t_{-} i}-S_{t}\right)=0$

457 This expresses that salinity is constant and equal to the salinity of the inflowing water $\left(\mathrm{S}_{\mathrm{t}}=\right.$ $458 \mathrm{~S}_{\mathrm{t}_{-} \mathrm{i}}$ ). In this model, LCDW is advected at all levels in the Weddell Gyre. It implies that the 459 Weddell Gyre must be filled only with LCDW. Nevertheless, the ${ }^{230} \mathrm{Th}_{\mathrm{t}}$ concentration in the 
460 Weddell Gyre changes with depth due to the scavenging transport of ${ }^{230} \mathrm{Th}_{\mathrm{t}}$ by sinking 461 particles. Hence, this mixing-scavenging model cannot represent the mixing of water masses 462 with different origins and labeled with different $\theta$ and $S$ signatures as they are observed along 463 the BGH section and elsewhere in the Southern Ocean. In principle, general circulation 464 models, associated or coupled with biogeochemical model, have the potential to reproduce the 465 coupled effect of scavenging and mixing, but the present generation of coupled models do not 466 accurately describe the vertical distribution of scavenging intensity (e.g.: Dutay et al., 2009, 467 Gu and Liu, 2017, Van Hulten et al., 2018).

4.2. Th isotopes along neutral density surfaces

While there are large horizontal concentration gradients of ${ }^{230} \mathrm{Th}_{\mathrm{d}}$ and total (dissolved + " particulate) ${ }^{230} \mathrm{Th}\left({ }^{230} \mathrm{Th}_{\mathrm{t}}\right)$ along the BGH section (mostly between station S3 to S5, Fig 3), ${ }^{230} \mathrm{Th}_{\mathrm{t}}$ concentration gradients are small on a given neutral density surface (Fig. 6). Figure 6 highlights that distribution of ${ }^{230} \mathrm{Th}_{\mathrm{d}}$ is mainly driven by transport from upwelling and mixing along isopycnal surfaces. There is more variability of ${ }^{232} \mathrm{Th}_{\mathrm{d}}$ or ${ }^{232} \mathrm{Th}_{\mathrm{t}}$ (dissolved + particulate ${ }^{232} \mathrm{Th}$ ) on a given neutral density value, presumably because large lithogenic inputs occur at stations S1 and S2 (Fig. 6).
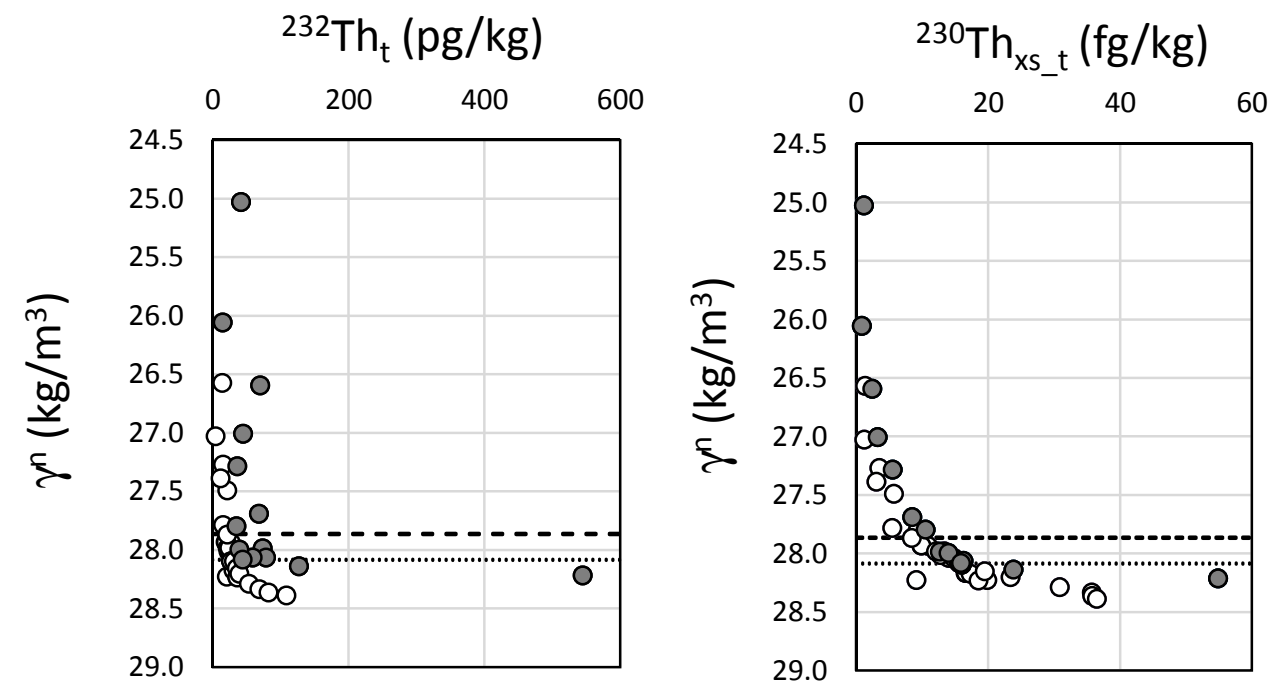
In the following, we discuss concentration changes along isopycnal surfaces. As these changes are small, we restrict this discussion to the Bonus GoodHope data, all generated in the same laboratory, in order to avoid the systematic inter-laboratory differences identified during the GEOTRACES intercalibration (Anderson et al., 2012).

We focus on 2 neutral density surfaces: $\gamma^{\mathrm{n}}=27.865 \mathrm{~kg} / \mathrm{m}^{3}$ and $\gamma^{\mathrm{n}}=28.094 \mathrm{~kg} / \mathrm{m}^{3}$ (Fig ES2). The neutral density surface $\gamma^{\mathrm{n}}=27.865 \mathrm{~kg} / \mathrm{m}^{3}$ can be followed from $\mathrm{z}=1500 \mathrm{~m}$ at station $\mathrm{S} 1$ to $\mathrm{z}=139 \mathrm{~m}$ at station S5. It crosses the following water masses: I-UCDW (S1), AUCDW (S2 and S3), DP-UCDW (S4) and AASW/WW (S5). The neutral density surface: $\gamma^{\mathrm{n}}=$ $28.094 \mathrm{~kg} / \mathrm{m}^{3}$ can be followed from $\mathrm{z}=3000 \mathrm{~m}$ at station $\mathrm{S} 1$ to $\mathrm{z}=200 \mathrm{~m}$ at station $\mathrm{S} 5$. It is close to the neutral density of the deep salinity maximum observed in 2004 along the same section (Gladyshev et al., 2008). It crosses the following water masses: SE-NADW (S1 and S2), SW-NADW/AABW (S3), LCDW (S4) and AASW/WW (S5).

We choose these two neutral density surfaces because: (1) they are found along the whole section, (2) samples along these surfaces tend to form a linear trend on a $\theta-S$ diagram, indicating a binary mixing (Fig. 7), and (3) they are not interrupted by the Agulhas Ridge. When, at a given station, no sample was collected exactly on the selected neutral density surface, concentrations were linearly interpolated between the samples collected just above and below this surface at the same station. When the particulate Th was not analyzed with in situ pump samples at the target depth or in its vicinity (e.g., intercal station), we used the ${ }^{232} \mathrm{Th}_{\mathrm{p}}$ concentration obtained with the Niskin filtration profiles and the ${ }^{230} \mathrm{Th}_{\mathrm{p}}$ was calculated with the $\left({ }^{230} \mathrm{Th}_{\mathrm{p}} /{ }^{232} \mathrm{Th}_{\mathrm{p}}\right)$ ratio linearly interpolated between the ratios measured on particles just above and below or at the nearby station:

$$
{ }^{230} \mathrm{Th}_{\mathrm{p} \text {-estimates }}={ }^{232} \mathrm{Th}_{\mathrm{p} \text {-Niskin filtration }} *\left({ }^{230} \mathrm{Th}_{\mathrm{p}} /{ }^{232} \mathrm{Th}_{\mathrm{p}}\right) \text { interpolated }
$$

\section{$\gamma^{\mathrm{n}}=27.865 \mathrm{~kg} / \mathrm{m}^{3}$}

On a $\theta-\mathrm{S}$ diagram, $\mathrm{S} 1, \mathrm{~S} 2, \mathrm{~S} 3$ and $\mathrm{S} 4$ plot along a straight line, suggesting a binary mixing between S1 and S4 (Fig. 7a). S5 does not fall on this line, possibly due to ocean-atmosphere interactions (Abadie et al., 2017), so that this station does not correspond to the same binary mixing along this neutral density surface. Therefore, in the following, we will apply the mixing model mostly between stations $\mathrm{S} 1$ and $\mathrm{S} 4$ for this isopycnal.

On a S- ${ }^{232} \mathrm{Th}_{\mathrm{t}}$ diagram, the stations $\mathrm{S} 3, \mathrm{~S} 4$ and intercal stand below the conservative mixing line between S1 and S4 (Fig. 7c). It corresponds to a depletion (net removal of ${ }^{232} \mathrm{Th}$ on 
517 sinking particles) of ${ }^{232} \mathrm{Th}_{\mathrm{t}}$ compared to a conservative mixing between S1 and S4: $\Delta^{232} \mathrm{Th}_{\mathrm{t}}<0$.

518 The strong ${ }^{232} \mathrm{Th}_{\mathrm{t}}$ inputs from the South African margin to the ACC are marked by a strong $519{ }^{232} \mathrm{Th}_{\mathrm{t}}$ concentration gradient $\left({ }^{232} \mathrm{Th}_{\mathrm{t}}\right.$ decrease by a factor $\sim 4$ between stations $\mathrm{S} 1$ and $\left.\mathrm{S} 4\right)$. A 520 small ${ }^{232} \mathrm{Th}_{\mathrm{t}}$ gradient between Station S5 and S4 suggests smaller inputs from the Weddell 521 Sea.

523 On a S- ${ }^{230} \mathrm{Th}_{\mathrm{t}}$ diagrams, there is much less change in ${ }^{230} \mathrm{Th}_{\mathrm{t}}$ concentration $(\sim 30 \%$ between 524 stations S1 and S4) compared to ${ }^{232} \mathrm{Th}_{\mathrm{t}}$ presumably because the margin is not a strong source 525 of ${ }^{230} \mathrm{Th}_{\mathrm{t}}$ for the ACC. Nevertheless, the ${ }^{230} \mathrm{Th}_{\mathrm{t}}$ concentrations generally decrease southward. 526 However, stations S2 and S3 stand above the conservative mixing line between S1 and S4 527 (Fig. 7e). This trend would correspond to an excess of ${ }^{230} \mathrm{Th}_{\mathrm{t}}$ compared to a conservative 528 mixing between $\mathrm{S} 1$ and $\mathrm{S} 4: \Delta^{230} \mathrm{Th}_{\mathrm{t}}>0$. There is an accumulation of ${ }^{230} \mathrm{Th}$ due to in situ production despite the net removal of ${ }^{232} \mathrm{Th}_{\mathrm{t}}$ during the same mixing process.

$\gamma^{\mathrm{n}}=28.094 \mathrm{~kg} / \mathrm{m}^{3}$

On a $\theta$-S diagram, S3, S4, intercal and S5 plot along a straight line, suggesting a binary mixing between S3 and S5 (Fig. 7b). S1 and S2 do not fall on this line, so that these 2 stations do not correspond to the same binary mixing along this neutral density surface. Therefore, in the following, we will restrict our analysis to stations S3 to S5 and, in the next section, we will apply the mixing model only between stations S3 and S5.

On a S-${ }^{232} \mathrm{Th}_{\mathrm{t}}$ diagram, we observe the same trend as on the previous isopycnal: a strong ${ }^{232} \mathrm{Th}_{\mathrm{t}}$ decrease from S1 to S3 and a weaker decrease from S5 to S4 (Fig 7d). This illustrates the role of the margins (and particularly the South African margin) as sources of ${ }^{232} \mathrm{Th}$ for the ACC. We argued in the previous paragraph that waters from stations S1 and S2 do not seem directly involved in the mixing observed further south. However, high ${ }^{232} \mathrm{Th}_{\mathrm{t}}$ concentrations are also observed in the SW-NADW sampled upstream of the BGH section.

543 These high values are acquired as this water flows along the Namibian margin (Scholten et 544 al., 2008) so that it could be a suitable ${ }^{232} \mathrm{Th}_{\mathrm{t}}$ source fueling the southern part of the BGH 545 section. S4 and intercal stations stand below the S3-S5 binary mixing line, reflecting ${ }^{232} \mathrm{Th}_{\mathrm{t}}$ 546 depletion at these 2 stations compared to conservative mixing, expressed as $\Delta^{232} \mathrm{Th}_{\mathrm{t}}<0$ (Fig 7). 547 More generally, paired ${ }^{232} \mathrm{Th}_{\mathrm{t}}-\mathrm{S}$ data indicates that there is a net $\mathrm{Th}$ removal by the settling 548 particles while water masses mix between stations S3 and S5. 
As for $\gamma^{\mathrm{n}}=27.865 \mathrm{~kg} / \mathrm{m}^{3}$, the relative variations of ${ }^{230} \mathrm{Th}_{\mathrm{t}}$ are small (Fig. 7f). On a S-

$551{ }^{230} \mathrm{Th}_{\mathrm{t}}$ diagram, the $\mathrm{S} 4$ and intercal stations stand above the $\mathrm{S} 3$-S5 binary conservative mixing 552 trend ( $\mathrm{S} 1$ and $\mathrm{S} 2$ are not considered because they are not involved in the mixing on this 553 isopycnal). This trend would correspond to an excess of ${ }^{230} \mathrm{Th}_{\mathrm{t}}$ compared to a conservative 554 mixing: $\Delta^{230} \mathrm{Th}_{\mathrm{t}}>0$. Like on the previous isopycnal, ${ }^{230} \mathrm{Th}$ accumulates due to in situ 555 production despite the net removal of ${ }^{232} \mathrm{Th}_{\mathrm{t}}$ during water mass mixing.

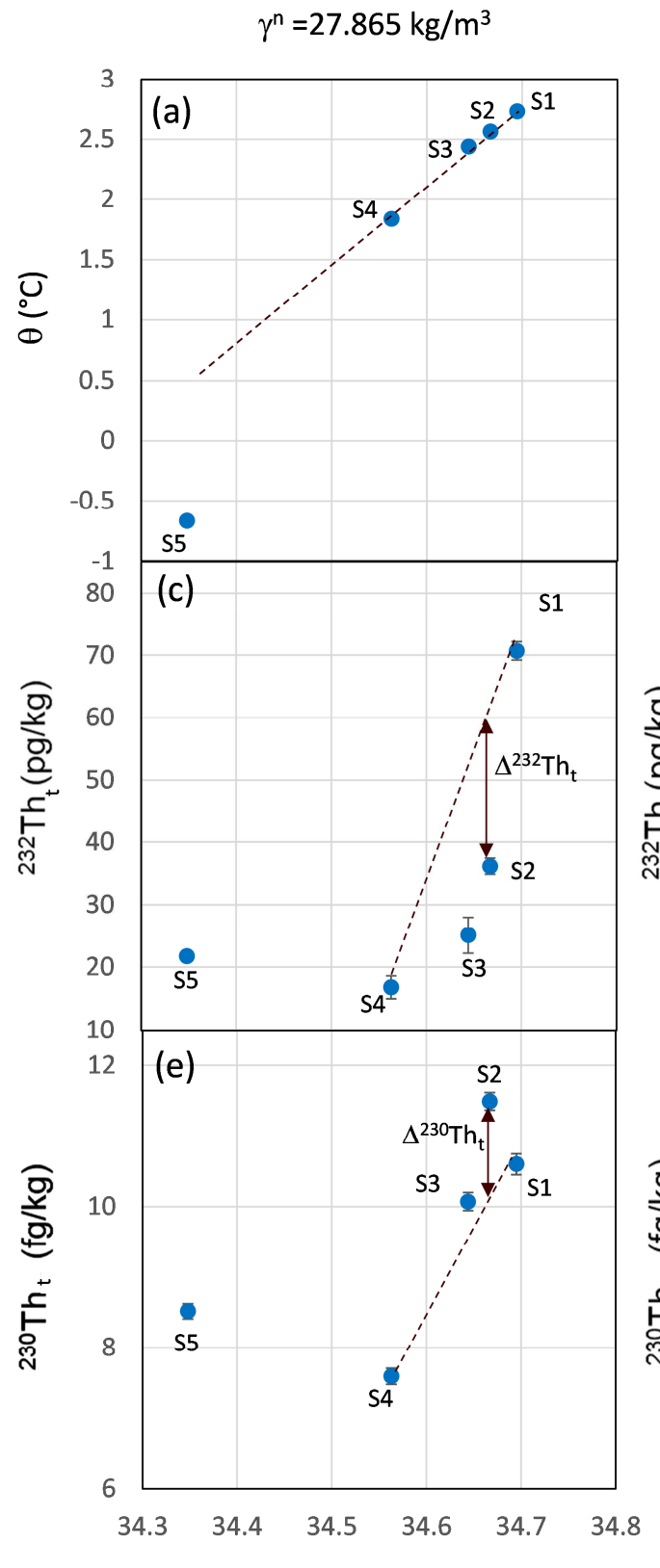

$\mathrm{S}$

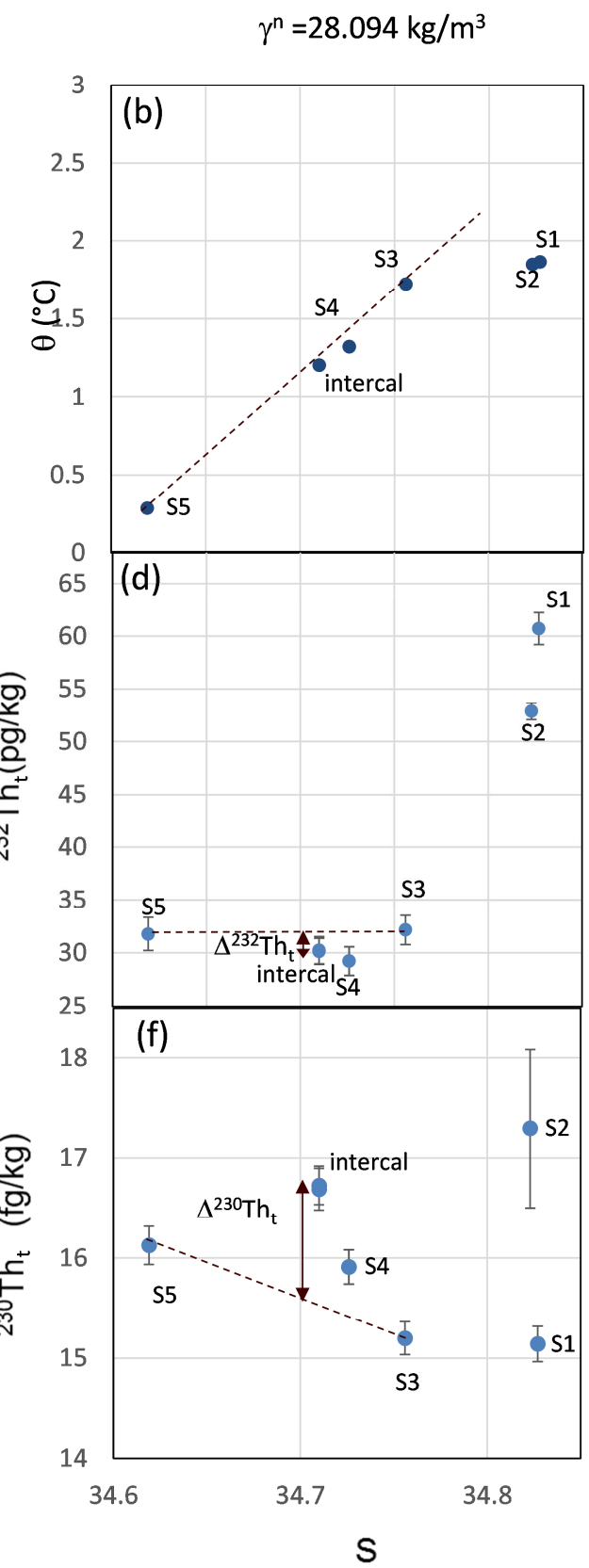

556

557 Figure 7: Potential temperature, ${ }^{232} \mathrm{Th}_{\mathrm{t}}$ and ${ }^{230} \mathrm{Th}_{\mathrm{t}}$ versus salinity on different neutral density surfaces. 558 Left: $\gamma^{\mathrm{n}}=27.865 \mathrm{~kg} / \mathrm{m}^{3}$. Right: $\gamma^{\mathrm{n}}=28.094 \mathrm{~kg} / \mathrm{m}^{3}$. a-b: Potential temperature versus salinity. c-d: ${ }^{232} \mathrm{Th}_{\mathrm{t}}$ 
559

560

561

562

563

564

565

566

567

568

569

570

571

572

573

574

575

576

577

578

579

580

581

582

583

584

585

586

587

588

589

590

versus salinity. e-f: ${ }^{230} \mathrm{Th}_{\mathrm{t}}$ versus salinity. Thin dashed line: conservative binary mixing line. Vertical double arrows denote the deviation compared to conservative mixing.

See table ES3 for the data calculated on isopycnals.

4.3. Modeling advection-diffusion-scavenging along a neutral density surface.

In the deep ocean, water mass mixing is thought to occur preferentially along isopycnal surfaces. There is both advection and eddy diffusion along the steep isopycnal surfaces of the Southern Ocean (Zika et al., 2009, Naveira Garabato et al., 2007). While diapycnal mixing is important in the Drake Passage due to the rough topography, it appears to be much weaker out of the passage (Watson et al., 2013), so we will neglect it for the present analysis. We approximate the combined effect of advection and diffusion along an isopycnal by extending the conservation equation (2) with the explicit introduction of advection and diffusion terms in an infinitesimal volume of water at steady state (Jenkins, 1987):

$K_{i} \frac{\partial^{2} C_{t}}{\partial x^{2}}-u_{i} \frac{\partial C_{t}}{\partial x}+P_{d}-w_{p}\left(\frac{\partial C_{p}}{\partial z}\right)=0$

Where $\mathrm{C}_{\mathrm{t}}$ is the total (dissolved + particulate) concentration of the tracer, $\mathrm{C}_{\mathrm{p}}$ the particulate concentration of the tracer, $\mathrm{K}_{\mathrm{i}}$ is the cross-stream isopycnal eddy diffusion coefficient and $\mathrm{u}_{\mathrm{i}}$ is the cross-stream isopycnal advection velocity. The $\mathrm{x}$-axis is parallel to the isopycnal surface in the meridional direction and oriented northward. The $\mathrm{z}$ axis is oriented perpendicular to the isopycnal surface and hence is almost vertical. Just like in the advection-scavenging model (equ. 3), keeping $\mathrm{w}_{\mathrm{p}}$ out of the partial derivative with respect to $\mathrm{z}$ (writing $w_{p}\left(\frac{\partial c_{p}}{\partial z}\right)$ instead of $\left.\left(\frac{\partial\left(w_{p} c_{p}\right)}{\partial z}\right)\right)$ requires to assume that $\mathrm{w}_{\mathrm{p}}$ does not vary with $\mathrm{z}$. We integrate Eq. 7 along isopycnal surfaces of the BGH section between the stations corresponding to the end members of water mass mixing (stations for S1 and S4 for $\gamma^{\mathrm{n}}=27.865 \mathrm{~kg} / \mathrm{m}^{3}$ and S3 and S5 for $\gamma^{\mathrm{n}}$ $=28.094 \mathrm{~kg} / \mathrm{m}^{3}$ ). Unlike most Th models that are built by vertically integrating the conservation equation, here we integrate the conservation equation along surfaces that are only slightly tilted relative to the horizontal. This is a simplified view of water transport because while water moves across the ACC, it is also rapidly advected eastward by the ACC (S2-S4) and the northern limb of the Weddell Gyre (S5). We assume that $\mathrm{K}_{\mathrm{i}}, \mathrm{u}_{\mathrm{i}}, \mathrm{w}_{\mathrm{p}}$ and $\left(\mathrm{dC}_{\mathrm{p}} / \mathrm{dz}\right)$ are all constant along $\mathrm{x}$ in order to obtain analytical solutions. We note $\mathrm{C}_{\mathrm{t}}=\mathrm{C}_{\mathrm{t} \text {-conc }}+$ $\Delta \mathrm{C}_{\mathrm{t}}$, where $\mathrm{C}_{\mathrm{t} \text {-conc }}$ is the concentration of the tracer if it had a conservative behavior and $\Delta \mathrm{C}_{\mathrm{t}}$ (as plotted in Fig 7) is the deviation of this tracer compared to a conservative behavior. The solution is then: 
$C_{t-\text { conc }}=\frac{e^{\frac{u_{i}}{K_{i}} x}-e^{\frac{u_{i}}{K_{i}} x_{B}}}{e^{\frac{u_{i}}{K_{i}} x_{A}}-e^{\frac{u_{i}}{K_{i}} x_{B}}}\left(C_{t_{-} A}-C_{\mathrm{t}_{-} B}\right)+C_{\mathrm{t}_{-} B}$

$\Delta C_{t}=\frac{\left(P_{d}-w_{p} \frac{d c_{p}}{d z}\right)}{u}\left(\left(x-x_{B}\right)+\left(x_{B}-x_{A}\right)\left(\frac{e^{\frac{u_{i}}{K_{i}}}-e^{\frac{u_{i}}{K_{i}} x_{B}}}{e^{\frac{u_{i}}{K_{i}}} x_{A}}-e^{\frac{u_{i}}{K_{i}} x_{B}}\right)\right)$

594

595

596 Here A and B represent stations S1 and S4 or S3 and S5 along the neutral density surface. For

597 a conservative tracer such as salinity, the concentration is given by:

598

$S=\frac{e^{\frac{u_{i}}{K_{i}}\left(x-x_{A}\right)}-1}{e^{\frac{u_{i}}{K_{i}}\left(x_{B}-x_{A}\right)}-1}\left(S_{B}-S_{A}\right)+S_{A}$

599
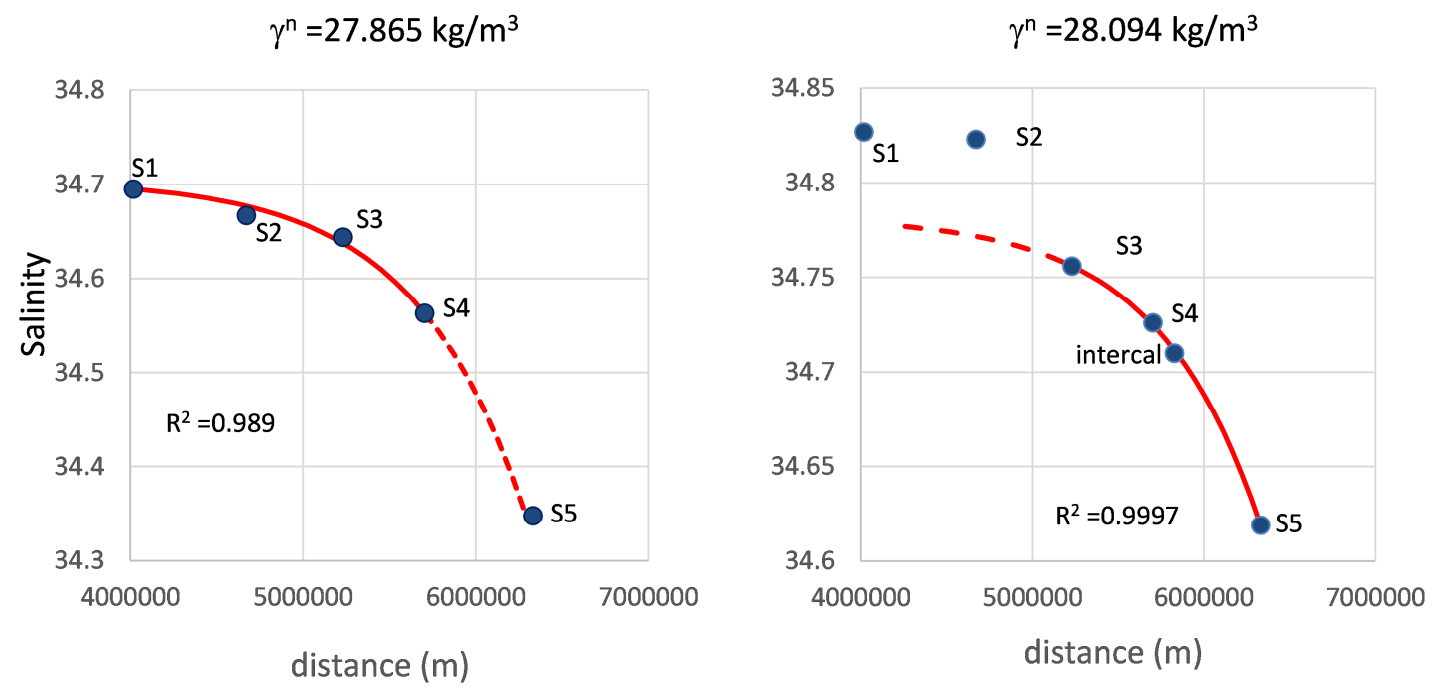

600

601

602 Figure 8: Advection-diffusion modelling of salinity. The distance considered is the meridian distance

603 from the equator ( $\mathrm{d}=0$ at the equator). Red curves are obtained with equation $10 . \mathrm{u}_{\mathrm{i}} / \mathrm{K}_{\mathrm{i}}$ is adjusted by

604 least squares just based on the stations corresponding to the 2-water mass values of $u_{i} / K_{i}$ are mixing

605 and by forcing the curves to pass through the 2 water mass end members. The values of $\mathrm{u}_{\mathrm{i}} / \mathrm{K}_{\mathrm{i}}$ are given

606 in Table 1. Dotted curves are extrapolated to the rest of the section but the corresponding stations are

607 not used to calculate the curve parameters.

608

609

610 

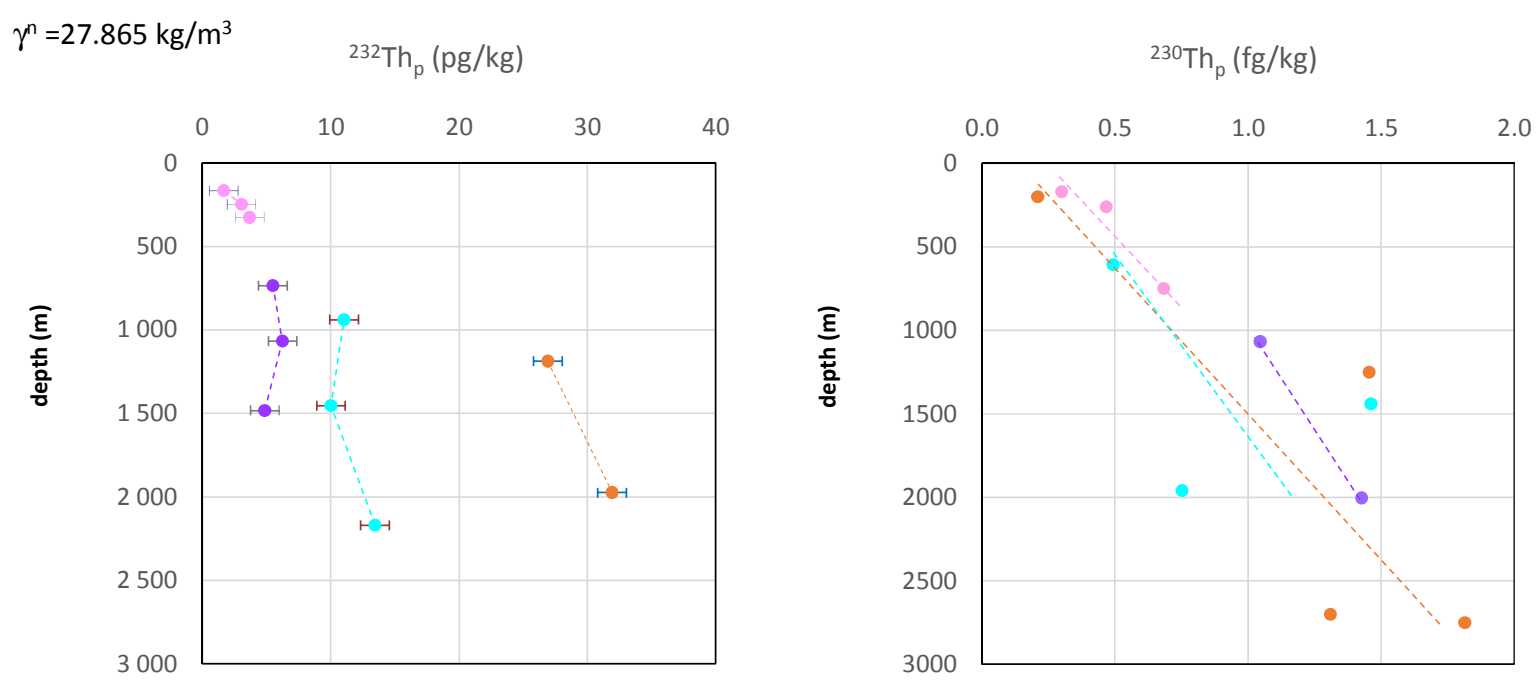

$\gamma^{n}=28.094 \mathrm{~kg} / \mathrm{m}^{3}$
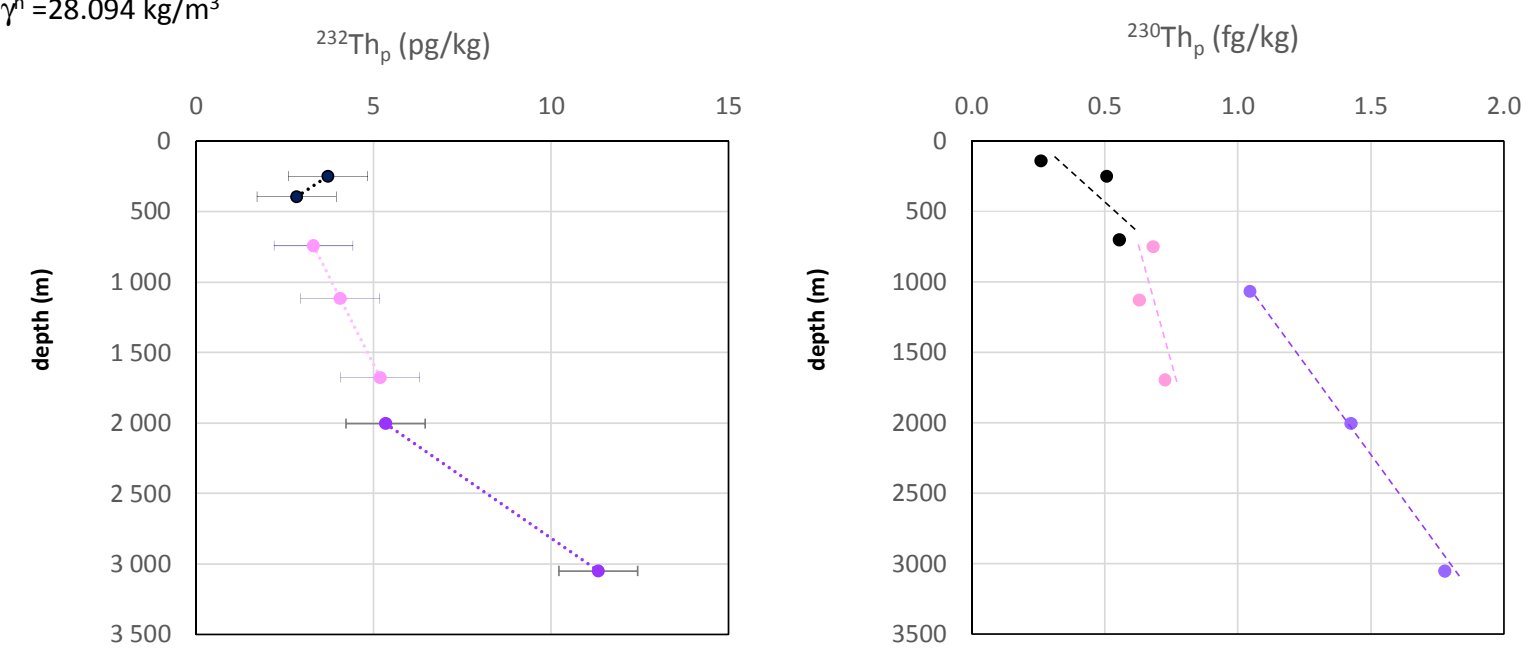

613 Figure 9: ${ }^{232} \mathrm{Th}_{\mathrm{p}}$ and ${ }^{230} \mathrm{Th}_{\mathrm{p}}$ profiles. For each isopycnal, we also plot the sample analyzed just above

614 and below in order to define the slopes $\left(\mathrm{d}^{232} \mathrm{Th}_{\mathrm{p}} / \mathrm{dz}\right)$ and $\left(\mathrm{d}^{230} \mathrm{Th}_{\mathrm{p}} / \mathrm{dz}\right)$, respectively. Color code is the

615 same as in Figure 3.

616

617

$618 \quad \gamma^{\mathrm{n}}=27.865 \mathrm{~kg} / \mathrm{m}^{3}$

619 Equation 10 allows determining the $\mathrm{u}_{\mathrm{i}} / \mathrm{K}_{\mathrm{i}}$ ratio using salinity data along the $\mathrm{BGH}$

620 section. For $\gamma^{\mathrm{n}}=27.865 \mathrm{~kg} / \mathrm{m}^{3}$, we obtain $\mathrm{u}_{\mathrm{i}} / \mathrm{K}_{\mathrm{i}}=-1.57 \times 10^{-6} \mathrm{~m}^{-1}$ (Fig. 8, Tab. 1). The minus

621 sign corresponds to a southward advection ( $\mathrm{u}_{\mathrm{i}}<0$ and $\mathrm{K}_{\mathrm{i}}$ is always positive). This is consistent

622 with the southward upwelling expected based on the average circulation of UCDW in the

623 Southern Ocean within this density range (section 2.1). This feature is observed for the 2

624 isopycnals studied here (see below for $\gamma^{\mathrm{n}}=28.094 \mathrm{~kg} / \mathrm{m}^{3}$ ). 

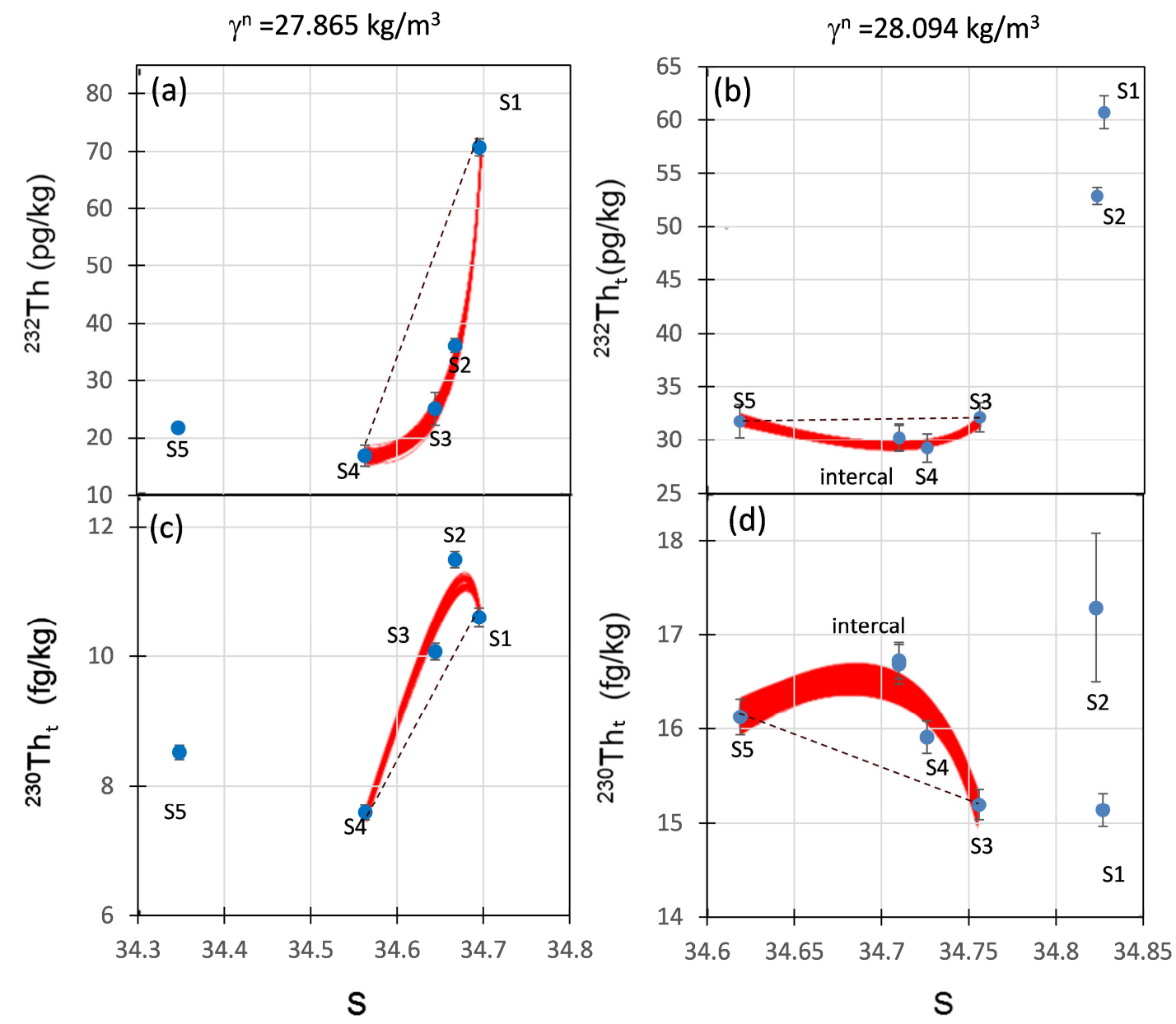

627

628 Figure 10: Advection-diffusion modelling of $\mathrm{S}$ and $\mathrm{Th}_{\mathrm{t}}$ isotopes compared to data. Staked red 629 curves: modelled curves with the highest $\mathrm{R}^{2}$ values (Tab. 1). Thin black dotted line: 630 conservative mixing between S3 and S5.

631

632

633 Tab. 1: Model parameters and outputs.

\begin{tabular}{|c|c|c|c|c|c|c|c|c|}
\hline & $\begin{array}{l}\mathrm{d}^{232} \mathrm{Th}_{\mathrm{p}} / \mathrm{dz} \\
(\mathrm{pg} / \mathrm{kg} / \mathrm{m})\end{array}$ & $\begin{array}{l}\mathrm{d}^{230} \mathrm{Th}_{\mathrm{p}} / \mathrm{dz} \\
(\mathrm{fg} / \mathrm{kg} / \mathrm{m})\end{array}$ & $\begin{array}{l}\mathrm{u}_{\mathrm{i}} / \mathrm{K}_{\mathrm{i}} \\
\left(\mathrm{m}^{-1}\right)\end{array}$ & $\begin{array}{l}\mathrm{K}_{\mathrm{i}} \\
\left(\mathrm{m}^{2} / \mathrm{s}\right)\end{array}$ & $\begin{array}{l}\mathrm{u}_{\mathrm{i}} \\
(\mathrm{m} / \mathrm{s})\end{array}$ & $\mathrm{w}_{\mathrm{p}}(\mathrm{m} / \mathrm{y})$ & $\mathrm{R}^{2}{ }_{-0}$ & $\mathrm{R}^{2} \_2$ \\
\hline $\begin{array}{l}\gamma^{\mathrm{n}}=27.865 \\
\mathrm{~kg} / \mathrm{m}^{3}\end{array}$ & $-0.001 /+0.012$ & $3.8 \times 10^{-4}-6.2 \times 10^{-4}$ & $-1.57 \times 10^{-6}$ & $\begin{array}{l}2000 \\
\pm 840\end{array}$ & $\begin{array}{l}-0.0033 \\
\pm 0.0014\end{array}$ & $674 \pm 250$ & $\sim 0.945$ & $\sim 0.994$ \\
\hline $\begin{array}{l}\gamma^{\mathrm{n}}=28.094 \\
\mathrm{~kg} / \mathrm{m}^{3}\end{array}$ & $+0.001 /+0.009$ & $0.4 \times 10^{-4}-3.5 \times 10^{-4}$ & $-1.65 \times 10^{-6}$ & $\begin{array}{l}2180 \\
\pm 480\end{array}$ & $\begin{array}{l}-0.0036 \\
\pm 0.0008\end{array}$ & $418 \pm 470$ & $\sim 0.806$ & $\sim 0.696$ \\
\hline
\end{tabular}

634

635 To determine $\mathrm{d}^{232} \mathrm{Th}_{\mathrm{p}} / \mathrm{dz}$, we use the Niskin filtration data because they have a better vertical

636 resolution. We determine $\mathrm{d}^{232} \mathrm{Th}_{\mathrm{p}} / \mathrm{dz}$ based on the ${ }^{232} \mathrm{Th}_{\mathrm{p}}$ concentrations measured above and 
637 below the depth of the neutral density surface at each station (Fig. 9). For $\gamma^{\mathrm{n}}=27.865 \mathrm{~kg} / \mathrm{m}^{3}$, $638 \mathrm{~d}^{232} \mathrm{Th}_{\mathrm{p}} / \mathrm{dz}$ varies strongly between $\mathrm{S} 1$ and $\mathrm{S} 4$. Interestingly, we obtain low $\mathrm{d}^{232} \mathrm{Th}_{\mathrm{p}} / \mathrm{dz}$ values 639 when the ${ }^{232} \mathrm{Th}_{\mathrm{t}}$ horizontal gradient is low (e.g., $\mathrm{d}^{232} \mathrm{Th}_{\mathrm{p}} / \mathrm{dz}=-0.001 \mathrm{pg} / \mathrm{kg} / \mathrm{m}$ at S3) and 640 higher $\mathrm{d}^{232} \mathrm{Th}_{\mathrm{p}} / \mathrm{dz}$ values when the ${ }^{232} \mathrm{Th}_{\mathrm{t}}$ horizontal gradient is high (e.g., $\mathrm{d}^{232} \mathrm{Th}_{\mathrm{p}} / \mathrm{dz}=+$ $6410.006 \mathrm{pg} / \mathrm{kg} / \mathrm{m}$ at S1). In other words, the increase of ${ }^{232} \mathrm{Th}_{\mathrm{t}}$ with depth is due to the horizontal 642 transport of ${ }^{232}$ Th by eddy diffusion from the margin, whereas without inputs from the 643 margins the dissolved and particulate ${ }^{232}$ Th concentration would be expected to be constant 644 with depth (Roy-Barman et al., 1996). Ideally, it would be best to integrate equation 7 with $645 \mathrm{~d}^{232} \mathrm{Th}_{\mathrm{p}} / \mathrm{dz}$ and $\mathrm{d}^{230} \mathrm{Th}_{\mathrm{p}} / \mathrm{dz}$ varying with $\mathrm{x}$. In practice, it is difficult to determine the evolution 646 of these gradients along the isopycnal or even to determine the exact average gradients 647 between stations S1 and S4. As a first approach, we will just use the range of the gradients 648 measured between $\mathrm{S} 1$ and $\mathrm{S} 4$ as input values to determine $\mathrm{w}_{\mathrm{p}}, \mathrm{u}_{\mathrm{i}}$ and $\mathrm{K}_{\mathrm{i}}$. For ${ }^{232} \mathrm{Th}$, we use a 649 range $\mathrm{d}^{232} \mathrm{Th}_{\mathrm{p}} / \mathrm{dz}$ from -0.001 to $+0.012 \mathrm{pg} / \mathrm{kg} / \mathrm{m}$ (Fig. 9, Tab. 1). For ${ }^{230} \mathrm{Th}$, most ${ }^{230} \mathrm{Th}_{\mathrm{p}}$ data 650 plot along a slope ranging between $3.8 \times 10^{-4} \mathrm{fg} / \mathrm{kg} / \mathrm{m}$ and $6.2 \times 10^{-4} \mathrm{fg} / \mathrm{kg} / \mathrm{m}$ (Fig. 9, Tab. 1).

651 We then estimate $\mathrm{w}_{\mathrm{p}}$ and $\mathrm{u}_{\mathrm{i}}$ with a least square approach. Using Monte Carlo 652 simulations, we maximize the coefficient of determination $\left(R^{2}\right)$ of the ${ }^{230}{ }^{2} h_{t}$ versus $S$ and $653{ }^{232} \mathrm{Th}_{\mathrm{t}}$ versus $\mathrm{S}$ curves simultaneously. In equation $9, \mathrm{w}_{\mathrm{p}}$ and the $\mathrm{dTh} / \mathrm{dz}$ terms are present as 654 products so that their opposite variations cancel each other. As a consequence, a relatively 655 large range of $\mathrm{w}_{\mathrm{p}}, \mathrm{d}^{230} \mathrm{Th}_{\mathrm{p}} / \mathrm{dz}$ and $\mathrm{d}^{232} \mathrm{Th}_{\mathrm{p}} / \mathrm{dz}$ values yield similar $\mathrm{R}^{2}$ values. Therefore, we 656 report $w_{p}$ and $u_{i}$ obtained for a range of high $R^{2}$ values. We obtain $w_{p}=674 \pm 250 \mathrm{~m} / \mathrm{y}$ and $u_{i}$ $657=-0.0033 \pm 0.0014 \mathrm{~m} / \mathrm{s}$. Using the $\mathrm{u}_{\mathrm{i}} / \mathrm{K}_{\mathrm{i}}$ ratio estimated previously, we deduce $\mathrm{K}_{\mathrm{i}}=2000 \pm$ $658 \quad 840 \mathrm{~m} / \mathrm{s}^{2}$.

659

660

661 $\gamma^{\mathrm{n}}=28.094 \mathrm{~kg} / \mathrm{m}^{3}$

662 For $\gamma^{\mathrm{n}}=28.094 \mathrm{~kg} / \mathrm{m}^{3}$, most of the ${ }^{230} \mathrm{Th}_{\mathrm{p}}$ data plot along a slope of $5 \times 10^{-4} \mathrm{fg} / \mathrm{kg} / \mathrm{m}$, 662 whereas ${ }^{232} \mathrm{Th}_{\mathrm{p}}$ data plot along a slope of $2 \times 10^{-4} \mathrm{pg} / \mathrm{kg} / \mathrm{m}$ (Fig. 10). In both diagrams, the 663 slope of the S4 station is poorly defined and potentially lower than the average. Using the 664 same method, we obtain $\mathrm{u}_{\mathrm{i}} / \mathrm{K}_{\mathrm{i}}=-1.65 \times 10^{-6} \mathrm{~m}^{-1}, \mathrm{w}_{\mathrm{p}}=435 \pm 324 \mathrm{~m} / \mathrm{y}, \mathrm{u}_{\mathrm{i}}=-0.0036 \pm 0.0008$ $665 \mathrm{~m} / \mathrm{s}$ and $\mathrm{K}_{\mathrm{i}}=2180 \pm 480 \mathrm{~m} / \mathrm{s}^{2}$ (Fig 8-9, Tab. 1).

667 The $2 \mathrm{~K}_{\mathrm{i}}$ values estimated here are on the upper end of the range (300 to $1800 \mathrm{~m}^{2} / \mathrm{s}$ ) reported 668 in the Southern Ocean, whereas $u_{i}$ is on the lower but of the same order of magnitude than an 
669

670

671

672

673

674

675

676

677

678

679

680

681

682

683

684

685

686

687

688

689

690

691

692

693

694

695

696 rate of ${ }^{230} \mathrm{Th}$.

697

698

699

700

701

estimate of the cross-stream horizontal velocity associated with the upwelling in the ACC ( $0.010 \pm 0.003 \mathrm{~m} / \mathrm{s}$, Naveira Garabato et al., 2007, Zika et al., 2009).

We have estimated $\mathrm{w}_{\mathrm{p}}$ at relatively close depths on the 2 isopycnals $\left(1200-1500 \mathrm{~m}\right.$ for $\gamma^{\mathrm{n}}=$ $27.865 \mathrm{~kg} / \mathrm{m}^{3}$ at stations S3 and S2 and 1000-1200 $\mathrm{m}$ for $\gamma^{\mathrm{n}}=28.094 \mathrm{~kg} / \mathrm{m}^{3}$ at stations intercal and S4, Fig. ES2). Taking the corresponding $\mathrm{w}_{\mathrm{p}}$ at face value (but keeping in mind that they strongly rely on the particulate concentration gradient estimate), it seems that there is a southward decrease of $\mathrm{w}_{\mathrm{p}}\left(\right.$ for $\gamma^{\mathrm{n}}=27.865, \mathrm{w}_{\mathrm{p}}=600 \mathrm{~m} / \mathrm{y}$ and for $\gamma^{\mathrm{n}}=28.094 \mathrm{~kg} / \mathrm{m}^{3}, \mathrm{w}_{\mathrm{p}}=300$ $\mathrm{m} / \mathrm{y})$. This southward decrease of settling speed seems consistent with the ${ }^{238} \mathrm{U}_{-}{ }^{234} \mathrm{Th}$ disequilibrium in the surface waters that decreased from the north to the south of the polar front zone (PFZ) during the BGH cruise (Planchon et al., 2013) and 2 weeks earlier on the same transect during the ANTXXIV/3 cruise (Rutgers van der Loeff et al., 2011). This gradient of the ${ }^{238} \mathrm{U}_{-}{ }^{234} \mathrm{Th}$ disequilibrium indicates a higher removal rate of ${ }^{234} \mathrm{Th}$ and suggests a higher particle settling velocity in the north compared the south of the PFZ.

It is rewarding that the particle settling speeds obtained with the isopycnal mixing model (which does not integrate the conservation equation over the water column) are in the range of the speeds generally obtained with the vertical 1D model (see section 4.1; Rutgers van der Loeff and Berger, 1993). In the 1D production-scavenging model, $\mathrm{w}_{\mathrm{p}}$ is given by (see section 4.1.): $\mathrm{w}_{\mathrm{p}}=\mathrm{P} /\left(\mathrm{d}^{230} \mathrm{Th}_{\mathrm{p}} / \mathrm{dz}\right)$. However, $\mathrm{w}_{\mathrm{p}}$ is usually obtained by averaging $\left(\mathrm{d}^{230} \mathrm{Th}_{\mathrm{p}} / \mathrm{dz}\right)$ over the whole water column or a large part of the water column as we did in section 4.1.

Consequently, the $\mathrm{w}_{\mathrm{p}}$ does not depend on sharp changes of $\left(\mathrm{d}^{230} \mathrm{Th}_{\mathrm{p}} / \mathrm{dz}\right)$ that could result from random errors on ${ }^{230} \mathrm{Th}_{\mathrm{p}}$ at intermediate depths. In the $1 \mathrm{D}$ mixing-scavenging model some advection is introduced but the model is still integrated from the surface to the seafloor, so that random errors on ${ }^{230} \mathrm{Th}_{\mathrm{p}}$ tend to be smoothed out (Rutgers van der Loeff and Berger, 1993). In addition, ${ }^{234} \mathrm{U}$ in situ decay is not the only source of dissolved ${ }^{230} \mathrm{Th}$, because advection also brings dissolved and particulate ${ }^{230} \mathrm{Th}$, which adds up uncertainty on the input

In the isopycnal mixing model presented here, the uncertainties cited above can have much larger effects on $\mathrm{w}_{\mathrm{p}}$ because $\left.\mathrm{i}\right)\left(\mathrm{d}^{230} \mathrm{Th}_{\mathrm{p}} / \mathrm{dz}\right)$ is calculated over much thinner depth ranges and ii) combined effects of high water flow rates and small ${ }^{230} \mathrm{Th}$ concentration gradients implies that the net effect of circulation on ${ }^{230} \mathrm{Th}$ transport is subject to large relative uncertainties. Nevertheless, the isopycnal mixing model opens the possibility to calculate the vertical 
evolution of $\mathrm{w}_{\mathrm{p}}$ in highly dynamical environments where the hypotheses of the 1D model are clearly not fulfilled.

In a recent series of paper, non-linear dissolved ${ }^{230} \mathrm{Th}$ profiles are modelled with a purely 1D approach by adjusting adsorption/desorption/remineralization rates and particle settling velocities that are assumed to vary with depth (Lerner et al., 2016, 2017 and 2018). These numerous parameters are adjusted by using different Th isotopes $\left({ }^{228} \mathrm{Th},{ }^{230} \mathrm{Th},{ }^{234} \mathrm{Th}\right)$. This approach is different but not inconsistent with our approach because: (1) Unlike the present paper, Lerner et al focus on areas where advection and eddy diffusion are expected to be negligible; (2) In the present paper, we make no hypothesis on the processes driving dissolved-particulate transfers (Eq. 7). Ultimately, it should be possible to determine adsorption/desorption rates in areas with weak currents and then to use these values in regions with a vigorous circulation such as the ACC. Lerner's approach treats explicitly the case of $\mathrm{w}_{\mathrm{p}}$ varying with depth, whereas our approach to leave the possibility to determine the particle settling speed at different depths/density. To do so rigorously, it will be necessary to treat $\mathrm{w}_{\mathrm{p}}$ like a parameter varying with depth (see section 4.3).

\section{Conclusion}

While we still used crude approximations, the model proposed here opens the possibility to determine the particle settling speed and to bring constraints on the isopycnal mixing rate at different vertical levels and with a more realistic description of the vertical structure of the water column. The improvement that will come out of the method proposed here will require sampling with higher horizontal and vertical sampling resolutions, a goal partly achieved in the framework of the GEOTRACES program. It also requires progresses for the particulate Th analysis and constant efforts for the intercalibration of the different cruises.

\section{9}




\section{Acknowledgements:}

734 The authors would like to thank S. Speich and M. Boyé, the chief scientists of the 735 BGH cruise, and the crew of the research vessel Marion Dufresne II (IPEV). We acknowledge 736 Christophe Guillerm, Lionel Scouarnec, Thomas Arsouze and Amandine Radic for the sample

737 collection on board. We are grateful to the 2 anonymous reviewers who improved the

738 manuscript with their very helpful comments. Support provided by the ANR (Programme

739 Blanc 2007: ANR- 07-BLAN-0146-02) and the INSU/CNRS (programme INSU/LEFE-

740 CYBER) is gratefully acknowledged.

741

742

743

744 
References :

Abadie, C., Lacan, F., Radic, A., Pradoux, C., Poitrasson, F., 2017. Iron isotopes reveal distinct dissolved iron sources and pathways in the intermediate versus deep Southern Ocean. Proceedings of the National Academy of Sciences, 114(5), 858-863.

Anderson, R.F., Fleisher, M.Q., Robinson, L.F., Edwards, R.L., Hoff, J. a., Moran, S.B., Loeff, M.R. Van Der, Thomas, A.L., Roy-Barman, M., Francois, R., 2012. GEOTRACES intercalibration of ${ }^{230} \mathrm{Th},{ }^{232} \mathrm{Th},{ }^{231} \mathrm{~Pa}$, and prospects for ${ }^{10} \mathrm{Be}$. Limnol. Oceanogr. Methods 10, 179-213.

Arhan, M., Mercier, H., Park, Y.-H., 2003. On the Deep Water circulation of the eastern South Atlantic Ocean. Deep-Sea Research Part I 50, 889-916.

Bacon, M.P., Anderson, R.F., 1982. Distribution of Thorium isotopes between dissolved and particulate forms in the deep sea. J. Geophys. Res. 87, 2045-2056. doi:10.1029/JC087iC03p02045

Bown, J., Boye, M., Baker, A., Duvieilbourg, E., Lacan, F., Le Moigne, F., ... Nelson, D. M., 2011. The biogeochemical cycle of dissolved cobalt in the Atlantic and the Southern Ocean south off the coast of South Africa. Marine Chemistry 126, 193-206.

Chever, F., Bucciarelli, E., Sarthou, G., Speich, S., Arhan, M., Penven, P., Tagliabue, A., 2010. Physical speciation of iron in the Atlantic sector of the Southern Ocean along a transect from the subtropical domain to the Weddell Sea Gyre. Journal of Geophysical Research: Oceans, 115(C10).

Chase, Z., Anderson, R. F., Fleisher, M. Q., Kubik, P. W., 2003. Scavenging of ${ }^{230} \mathrm{Th},{ }^{231} \mathrm{~Pa}$ and ${ }^{10} \mathrm{Be}$ in the Southern Ocean (SW Pacific sector): The importance of particle flux, particle composition and advection. Deep Sea Research Part II: Topical Studies in Oceanography 50, 739-768.

Coppola, L., Roy-Barman, M., Mulsow, S., Povinec, P., Jeandel, C., 2006. Thorium isotopes as tracers of particles dynamics in the Indian sector of the Southern Ocean. Marine Chemistry 100, 299-313

Dutay, J.-C., Lacan, F., Roy Barman, M. and Bopp, L., 2009. The influence of particle size and type on ${ }^{231} \mathrm{~Pa}$ and ${ }^{230} \mathrm{Th}$ simulation with a global coupled biogeochemical- ocean general circulation model: a first approach. G-cubed, doi:10.1029/2008GC002291

Garcia-Solsona, E., Jeandel, C., Labatut, M., Lacan, F., Vance, D., Chavagnac, V., Pradoux, C., 2014. Rare earth elements and $\mathrm{Nd}$ isotopes tracing water mass mixing and particleseawater interactions in the SE Atlantic. Geochimica et Cosmochimica Acta, 125, 351-372.

Gdaniec, S., Roy-Barman, M., Foliot, L., Thil, F., Dapoigny, A., Burckel, P, A. Masque, P., Garcia-Orellana, J., Morth, M., Andersson, P. S., 2018. Thorium and protactinium isotopes as tracers of marine particle fluxes and deep water circulation in the Mediterranean Sea. Marine Chemistry 199, 12-23.

Gdaniec, S., Roy-Barman, M., Levier, M., Valk O., Rutgers van der Loeff, M., Foliot, L., Dapoigny, A., Morth, M., Andersson, P. S., 2019. ${ }^{231} \mathrm{~Pa}$ and ${ }^{230} \mathrm{Th}$ in the Arctic Ocean: implications for Boundary Scavenging and ${ }^{231} \mathrm{~Pa}^{2}{ }^{230} \mathrm{Th}$ fractionation in the Eurasian Basin. Submitted to Chemical Geology

Gladyshev S., Arhan M., Sokov A., Speich S., 2008. A hydrographic section from South Africa to the southern limit of the Antarctic Circumpolar Current at the Greenwich meridian. Deep-Sea Res. I 55, 1284-1303. 
Gu, S., Liu, Z., 2017. ${ }^{231} \mathrm{~Pa}$ and ${ }^{230} \mathrm{Th}$ in the ocean model of the Community Earth System Model (CESM1.3), Geosci. Model Dev., 10, 4723-4742

Jeandel, C., Venchiarutti, C., Bourquin, M., Pradoux, C., Lacan, F., van Beek, P., Riotte, J., 2011. Single column sequential extraction of Ra, $\mathrm{Nd}, \mathrm{Th}, \mathrm{Pa}$ and $\mathrm{U}$ from a natural sample. Geostand. Geoanalytical Res. 35, 449-459.

Jenkins, W. J., 1987. ${ }^{3} \mathrm{H}$ and ${ }^{3} \mathrm{He}$ in the Beta Triangle: Observations of gyre ventilation and oxygen utilization rates. J. Phys. Oceanogr. 17, 763-783.

Lerner, P., Marchal, O., Lam, P. J., Anderson, R. F., Buesseler, K., Charette, M. A., Edwards, R. L., Hayes, C. T., Huang, K. F., Lu, Y., Robinson, L. F., Solow, A., 2016. Testing models of thorium and particle cycling in the ocean using data from station GT11-22 of the US GEOTRACES North Atlantic Section, Deep Sea Research Part I: Oceanographic Research Papers, 113, 57-79.

Lerner, P., Marchal, O., Lam, P. J., Buesseler, K., Charette, M., 2017. Kinetics of thorium and particle cycling along the US GEOTRACES North Atlantic Transect. Deep Sea Research Part I: Oceanographic Research Papers, 125, 106-128.

Lerner, P., Marchal, O., Lam, P. J., Solow, A., 2018. Effects of particle composition on thorium scavenging in the North Atlantic. Geochimica et Cosmochimica Acta, 233, 115134.

Marshall, J., Speer, K., 2012. Closure of the meridional overturning circulation through Southern Ocean upwelling. Nature Geoscience 5, 171-180.

Naveira Garabato, A.C., Stevens, D.P., Watson, A.J. and Roether, W., 2007. Short-circuiting of the overturning circulation in the Antarctic Circumpolar Current. Nature 447|, 194-197.

Nozaki, Y., Horibe, Y., Tsubota, H., 1981. The water column distribution of thorium isotopes in the western North Pacific, Earth Planet. Sc. Lett., 54, 203-216.

Planchon, F., Cavagna, A. J., Cardinal, D., André, L., Dehairs, F., 2013. Late summer particulate organic carbon export and twilight zone remineralisation in the Atlantic sector of the Southern Ocean. Biogeosciences 10, 803-820.

Planquette, H., Sherrell, R. M., 2012. Sampling for particulate trace element determination using water sampling bottles: methodology and comparison to in situ pumps. Limnology and Oceanography: methods 10, 367-388.

Roy-Barman, M., 2009. Modelling the effect of boundary scavenging on Thorium and Protactinium profiles in the ocean. Biogeosciences 6, 7853-7896.

Roy-Barman, M., Chen, J.H., Wasserburg, G.J., 1996. The sources and the fates of thorium. Earth Planet. Sci. Lett. 139, 351-363.

Roy-Barman, M., Coppola, L., Souhaut, M., 2002. Thorium isotopes in the western Mediterranean Sea: An insight into the marine particle dynamics. Earth Planet. Sci. Lett. $196,161-174$.

Rutgers van der Loeff, M.M., Berger, G.W., 1993. Scavenging of ${ }^{230}$ Th and ${ }^{231} \mathrm{~Pa}$ near the antarctic polar front in the South Atlantic. Deep. Res. Part I 40, 339-357

Rutgers van der Loeff, R., Cai, P. H., Stimac, I., Bracher, A., Middag, R., Klunder, M. B., \& van Heuven, S. M., 2011. ${ }^{234} \mathrm{Th}$ in surface waters: distribution of particle export flux across the Antarctic Circumpolar Current and in the Weddell Sea during the GEOTRACES expedition ZERO and DRAKE. Deep Sea Research Part II: Topical Studies in Oceanography 58, 2749-2766. 
Rutgers van der Loeff, M., Venchiarutti, C., Stimac, I., van Ooijen, J., Huhn, O., Rohardt, G., \& Strass, V., 2016. Meridional circulation across the Antarctic Circumpolar Current serves as a double ${ }^{231} \mathrm{~Pa}$ and ${ }^{230} \mathrm{Th}$ trap. Earth and Planetary Science Letters, 455, 73-84.

Schlitzer, R., 2007. Ocean data view. http://odv. awi. de.

Scholten, J. C., Fietzke, J., Mangini, A., Garbe-Schönberg, C. D., Eisenhauer, A., Schneider, R., Stoffers, P., 2008. Advection and scavenging: Effects on 230Th and 231Pa distribution off Southwest Africa. Earth and Planetary Science Letters, 271(1), 159-169.

Sims, K. W., Gill, J. B., Dosseto, A., Hoffmann, D. L., Lundstrom, C. C., Williams, R. W., ... Glessner, J. J., 2008. An inter-laboratory assessment of the thorium isotopic composition of synthetic and rock reference materials. Geostandards and Geoanalytical Research 32, 65-91.

Sokolov, S., Rintoul, S. R., 2009. Circumpolar structure and distribution of the Antarctic Circumpolar fronts: 1. Mean circumpolar path, J. Geophys. Res., 114, C11018, doi:10.1029/2008JC005108.

Thomas, A.L., Henderson, G.M., Robinson, L.F., 2006. Interpretation of the 231Pa/230Th paleocirculation proxy: new water-column measurements from the southwest Indian Ocean. Earth Planet. Sci. Lett. 241, 493.

van Hulten, M. M. P., Dutay, J. C., Roy-Barman, 2018. A global scavenging and circulation ocean model of thorium-230 and protactinium-231 with an improved particle dynamics (NEMO-ProThorP 0.1). Goescientific model development 11, 3537-3556.

Venchiarutti, C., Jeandel C., Roy-Barman, M., 2008. Particle dynamics in the wake of Kerguelen Island traced by thorium isotopes (Southern Ocean, KEOPS program). Deep Sea Research I 55, 1343-1363

Venchiarutti, C., van der Loeff, M.R., Stimac, I., 2011. Scavenging of ${ }^{231} \mathrm{~Pa}$ and thorium isotopes based on dissolved and size-fractionated particulate distributions at Drake Passage (ANTXXIV-3). Deep. Res. Part II Top. Stud. Oceanogr. 58, 2767-2784.

Walter, H.J., Rutgers van der Loeff, M.M., Hoeltzen, H., 1997. Enhanced scavenging of ${ }^{231} \mathrm{~Pa}$ relative to ${ }^{230} \mathrm{Th}$ in the South Atlantic south of the Polar Front: Implications for the use of the ${ }^{231} \mathrm{~Pa} /{ }^{230} \mathrm{Th}$ ratio as a paleoproductivity proxy. Earth Planet. Sci. Lett. 149, 85-100.

Watson A. J., Ledwell J. R., Messias M. J., King B. A., Mackay N., Meredith M. P., Mills B., and Garabato A. C. N., 2013. Rapid cross-density ocean mixing at mid depths in Drake Passage measured by tracer release. Nature 501, 408-413.

Zika, J. D., Sloyan, B. M. \& McDougall, T. J., 2009. Diagnosing the Southern Ocean overturning from tracer fields. J. Phys. Oceanogr. 39, 2926-2940. 
877 Table ES1: Dissolved Thorium data.

\begin{tabular}{|c|c|c|c|c|c|c|c|c|}
\hline Station & $\begin{array}{c}\text { Depth } \\
(\mathrm{m})\end{array}$ & $\begin{array}{c}\theta \\
\left({ }^{\circ} \mathrm{C}\right) \\
\end{array}$ & Salinity & $\begin{array}{c}\gamma^{n} \\
\left(\mathrm{~kg} / \mathrm{m}^{3}\right)\end{array}$ & $\begin{array}{l}{ }^{232} \mathrm{Th}_{\mathrm{d}}{ }^{1} \\
(\mathrm{pg} / \mathrm{kg})\end{array}$ & $\begin{array}{l}{ }^{230} \mathrm{Th}_{\mathrm{p}}{ }^{1} \\
(\mathrm{pg} / \mathrm{kg})\end{array}$ & $\begin{array}{c}{ }^{230} \mathrm{Th}_{\mathrm{p}-\mathrm{xs}}{ }^{2} \\
(\mathrm{pg} / \mathrm{kg})\end{array}$ & Water mass \\
\hline \multicolumn{9}{|c|}{ S1: $36.50^{\circ} \mathrm{S}, 13.10^{\circ} \mathrm{E}, 4923 \mathrm{~m}$ bottom depth } \\
\hline & 29 & 20.785 & 35.617 & 25.0222 & $34.7 \pm 1.3$ & $1.21 \pm 0.03$ & $1.06 \pm 0.03$ & ICW \\
\hline & 198 & 12.364 & 35.014 & 26.53 & $52.1 \pm 1.3$ & $2.48 \pm 0.04$ & $2.25 \pm 0.04$ & ICW \\
\hline & 397 & 9.824 & 34.757 & 26.7918 & $50.1 \pm 1.5$ & $4.52 \pm 0.06$ & $4.30 \pm 0.06$ & ICW \\
\hline & 753 & 4.973 & 34.346 & 27.1602 & $37.2 \pm 1.3$ & $5.45 \pm 0.08$ & $5.29 \pm 0.08$ & i-AAIW \\
\hline & 1188 & 3.279 & 34.551 & 27.5004 & $38.0 \pm 1.3$ & $7.38 \pm 0.12$ & $7.22 \pm 0.12$ & i-AAIW \\
\hline & 1975 & 2.515 & 34.808 & 27.7752 & $40.2 \pm 1.4$ & $11.64 \pm 0.18$ & $11.46 \pm 0.18$ & SE-NADW \\
\hline & 2664 & 2.132 & 34.838 & 27.8316 & $42.0 \pm 1.3$ & $14.71 \pm 0.19$ & $14.52 \pm 0.19$ & SE-NADW \\
\hline & 3005 & 1.945 & 34.836 & 27.8444 & $42.2 \pm 1.4$ & $14.94 \pm 0.17$ & $14.76 \pm 0.17$ & SE-NADW \\
\hline & 3981 & 0.892 & 34.749 & 27.8506 & $70.0 \pm 1.4$ & $17.55 \pm 0.23$ & $17.25 \pm 0.23$ & AABW \\
\hline & 4565 & 0.716 & 34.733 & 27.8493 & $69.1 \pm 1.6$ & $21.70 \pm 0.27$ & $21.40 \pm 0.27$ & AABW \\
\hline & 4907 & 0.568 & 34.72 & 27.8481 & $288.5 \pm 3.5$ & $37.10 \pm 0.41$ & $35.84 \pm 0.41$ & AABW \\
\hline \multicolumn{9}{|c|}{$\mathrm{S} 2: 42.47^{\circ} \mathrm{S}, 08.93^{\circ} \mathrm{E}, 4070 \mathrm{~m}$ bottom depth } \\
\hline & 20 & 12.951 & 34.521 & 26.0547 & $11.1 \pm 1.4$ & $0.74 \pm 0.02$ & $0.70 \pm 0.03$ & ICW \\
\hline & 124 & 9.083 & 34.482 & 26.7815 & $19.8 \pm 1.4$ & $1.84 \pm 0.03$ & $1.75 \pm 0.04$ & ICW \\
\hline & 292 & 6.654 & 34.267 & 27.0053 & $36.2 \pm 1.3$ & $3.04 \pm 0.04$ & $2.89 \pm 0.04$ & ICW/a-AAIW \\
\hline & 398 & 6.01 & 34.292 & 27.1231 & $38.8 \pm 1.5$ & $4.13 \pm 0.06$ & $3.97 \pm 0.06$ & ICW/a-AAIW \\
\hline & 595 & 4.138 & 34.185 & 27.2829 & $30.9 \pm 1.4$ & $5.14 \pm 0.08$ & $5.01 \pm 0.08$ & a-AAIW \\
\hline & 940 & 3.075 & 34.313 & 27.5162 & $25.7 \pm 1.3$ & $7.02 \pm 0.09$ & $6.90 \pm 0.09$ & a-AAIW \\
\hline & 1453 & 2.626 & 34.585 & 27.7945 & $26.1 \pm 1.3$ & $9.19 \pm 0.11$ & $9.07 \pm 0.11$ & UCDW \\
\hline & 2172 & 2.346 & 34.79 & 27.994 & $31.1 \pm 1.3$ & $13.36 \pm 0.16$ & $13.22 \pm 0.16$ & SE-NADW \\
\hline & 2905 & 1.967 & 34.827 & 28.0789 & $35.8 \pm 1.3$ & $14.43 \pm 0.16$ & $14.28 \pm 0.16$ & SE-NADW \\
\hline & 3445 & 1.427 & 34.792 & 28.1359 & $36.9 \pm 1.6$ & $16.13 \pm 0.24$ & $15.96 \pm 0.24$ & SE-NADW \\
\hline & 4021 & 0.81 & 34.741 & 28.1961 & $63.9 \pm 1.5$ & $17.96 \pm 0.22$ & $17.68 \pm 0.22$ & AABW \\
\hline \multicolumn{9}{|c|}{ S3: $47.55^{\circ} \mathrm{S}, 04.37^{\circ} \mathrm{E}, 4480 \mathrm{~m}$ bottom depth } \\
\hline & 40 & 6.32 & 33.733 & 26.5685 & $7.5 \pm 1.4$ & $1.19 \pm 0.04$ & $1.15 \pm 0.04$ & AASW \\
\hline & 124 & 4.029 & 33.867 & 27.0072 & $8.3 \pm 1.3$ & $1.82 \pm 0.04$ & $1.79 \pm 0.04$ & AASW \\
\hline & 248 & 3.633 & 34.101 & 27.2697 & $15.3 \pm 1.4$ & $3.55 \pm 0.07$ & $3.48 \pm 0.07$ & AASW/a-AAIW \\
\hline & 495 & 2.739 & 34.233 & 27.4888 & $17.1 \pm 1.2$ & $5.07 \pm 0.07$ & $5.00 \pm 0.07$ & a-AAIW \\
\hline & 742 & 2.591 & 34.407 & 27.6574 & $16.8 \pm 1.3$ & $6.46 \pm 0.11$ & $6.39 \pm 0.11$ & a-AAIW/UCDW \\
\hline & 1068 & 2.447 & 34.575 & 27.8099 & $18.2 \pm 1.3$ & $8.26 \pm 0.10$ & $8.18 \pm 0.10$ & A_UCDW \\
\hline & 1482 & 2.334 & 34.716 & 27.936 & $22.2 \pm 1.5$ & $10.93 \pm 0.17$ & $10.83 \pm 0.17$ & SW-NADW \\
\hline & 2003 & 1.971 & 34.771 & 28.0376 & $23.2 \pm 1.2$ & $12.68 \pm 0.15$ & $12.58 \pm 0.15$ & SW-NADW \\
\hline & 2003 & & & & $23.2 \pm 1.5$ & $13.45 \pm 0.16$ & $13.34 \pm 0.16$ & \\
\hline & 3052 & 0.955 & 34.731 & 28.1653 & $29.2 \pm 1.6$ & $14.94 \pm 0.19$ & $14.81 \pm 0.19$ & SW-NADW \\
\hline & 4299 & 0.415 & 34.695 & 28.2262 & $18.5 \pm 1.3$ & $8.83 \pm 0.12$ & $8.75 \pm 0.12$ & AABW \\
\hline
\end{tabular}


S4: $51.85^{\circ} \mathrm{S}, 00.00^{\circ} \mathrm{E}, 2570 \mathrm{~m}$ bottom depth

$\begin{array}{cccccccl}59 & 2.521 & 33.712 & 27.0277 & 4.7 \pm 1.5 & 1.20 \pm 0.03 & 1.18 \pm 0.03 & \text { AASW } \\ 168 & 0.827 & 34.033 & 27.4838 & 10.8 \pm 1.5 & 2.82 \pm 0.06 & 2.77 \pm 0.06 & \text { WW (AASW) } \\ 248 & 1.543 & 34.433 & 27.7832 & 13.4 \pm 1.6 & 5.04 \pm 0.08 & 4.98 \pm 0.08 & \text { WW/DP-UCDW } \\ 327 & 1.811 & 34.548 & 27.8553 & 13.8 \pm 1.6 & 6.64 \pm 0.10 & 6.58 \pm 0.10 & \text { DP-UCDW } \\ 416 & 1.874 & 34.627 & 27.9165 & 17.4 \pm 1.3 & 8.68 \pm 0.10 & 8.61 \pm 0.10 & \text { DP-UCDW } \\ 416 & 1.874 & 34.627 & 27.9165 & 15.7 \pm 1.3 & 7.94 \pm 0.10 & 7.87 \pm 0.10 & \text { DP-UCDW } \\ 742 & 1.702 & 34.704 & 28.012 & 21.5 \pm 1.5 & 12.16 \pm 0.14 & 12.06 \pm 0.14 & \text { LCDW } \\ 1117 & 1.42 & 34.727 & 28.08 & 27.3 \pm 1.3 & 15.28 \pm 0.17 & 15.16 \pm 0.17 & \text { LCDW } \\ 1678 & 0.755 & 34.704 & 28.171 & 28.6 \pm 1.5 & 16.70 \pm 0.19 & 16.58 \pm 0.19 & \text { LCDW/AABW } \\ 2307 & 0.359 & 34.689 & 28.225 & 30.5 \pm 1.4 & 18.11 \pm 0.21 & 17.98 \pm 0.21 & \text { AABW } \\ 2501 & 0.319 & 34.687 & 28.231 & 30.1 \pm 1.3 & 16.82 \pm 0.19 & 16.69 \pm 0.19 & \text { AABW }\end{array}$

Intercal: $\quad 52.98^{\circ} \mathrm{S}, 00.00^{\circ} \mathrm{W}, 2624 \mathrm{~m}$ bottom depth

$\begin{array}{cccccccc}380 & 1.81 & 34.63 & 27.929 & 19.1 \pm 1.2 & 9.93 \pm 0.13 & 9.85 \pm 0.13 & \text { UCDW } \\ 380 & 1.81 & 34.63 & 27.929 & 19.6 \pm 1.4 & 9.90 \pm 0.12 & 9.82 \pm 0.12 & \text { UCDW } \\ 500 & 1.78 & 34.68 & 27.979 & 22.0 \pm 1.2 & 12.14 \pm 0.14 & 12.05 \pm 0.14 & \text { LCDW } \\ 500 & 1.78 & 34.68 & 27.979 & 24.5 \pm 1.5 & 13.44 \pm 0.20 & 13.33 \pm 0.20 & \text { LCDW } \\ 1000 & 1.22 & 34.71 & 28.094 & 27.4 \pm 1.2 & 16.08 \pm 0.20 & 15.96 \pm 0.20 & \text { LCDW } \\ 1000 & 1.22 & 34.71 & 28.094 & 27.5 \pm 1.3 & 16.11 \pm 0.18 & 15.99 \pm 0.18 & \text { LCDW }\end{array}$

S5: $57.55^{\circ} \mathrm{S}, 00.03^{\circ} \mathrm{W}, 3932 \mathrm{~m}$ bottom depth

\begin{tabular}{lcccccll}
134 & -0.671 & 34.355 & 27.8713 & $19.7 \pm 1.5$ & $8.26 \pm 0.11$ & $8.17 \pm 0.11$ & WW (AASW) \\
247 & 0.353 & 34.63 & 28.094 & $29.4 \pm 1.5$ & $15.64 \pm 0.19$ & $15.51 \pm 0.19$ & WW (AASW)/ WDW \\
396 & 0.529 & 34.674 & 28.154 & $32.8 \pm 1.4$ & $19.10 \pm 0.24$ & $18.96 \pm 0.24$ & WDW \\
692 & 0.422 & 34.685 & 28.202 & $36.1 \pm 1.5$ & $23.00 \pm 0.24$ & $22.84 \pm 0.24$ & WDW \\
1185 & 0.154 & 34.677 & 28.2434 & $42.2 \pm 1.5$ & $26.59 \pm 0.29$ & $26.41 \pm 0.29$ & WDW / WSDW \\
1776 & -0.104 & 34.668 & 28.2872 & $49.4 \pm 1.6$ & $30.31 \pm 0.32$ & $30.10 \pm 0.32$ & WDW / WSDW \\
2462 & -0.346 & 34.66 & 28.332 & $60.6 \pm 1.4$ & $34.30 \pm 0.36$ & $34.04 \pm 0.36$ & WSDW \\
3147 & -0.502 & 34.655 & 28.3619 & $71.5 \pm 1.6$ & $34.42 \pm 0.36$ & $34.10 \pm 0.36$ & WSDW \\
3848 & -0.632 & 34.65 & 27.8713 & $83.1 \pm 1.6$ & $33.93 \pm 0.37$ & $33.57 \pm 0.37$ & WSDW / WSBW \\
3848 & -0.632 & 34.65 & 27.8713 & $82.5 \pm 1.8$ & $33.78 \pm 0.38$ & $33.42 \pm 0.38$ & WSDW / WSBW \\
\hline
\end{tabular}

887 1: Uncertainties are $2 \sigma_{\mathrm{n}}$ (error on the mean). ${ }^{2}$ : The excess ${ }^{230} \mathrm{Th}_{\mathrm{d}-\mathrm{xs}}$ is calculated using the 888 equation:

$889{ }^{230} T h_{d-x s}={ }^{230} T h_{d-\text { measured }}-{ }^{232} T h_{d-\text { measured }} \times\left(\frac{{ }^{230} \mathrm{Th}}{{ }^{232} \mathrm{Th}}\right)_{\text {Lithogenic }}$, where the

$890 \quad\left({ }^{230} \mathrm{Th} /{ }^{232} \mathrm{Th}\right)_{\text {Litogenic }}=4.0 \times 10^{-6}(\mathrm{~mol} / \mathrm{mol})$, close to average crust $\left.{ }^{230} \mathrm{Th} /{ }^{232} \mathrm{Th}=4.1 \times 10^{-6}\right)$.

891 The lithogenic correction is small: generally less than $2 \%$ of ${ }^{230} \mathrm{Th}_{\mathrm{d}}$ and occasionally reaching

8926 to $11 \%$ in the surface waters of S2 and S1 respectively. Therefore the ${ }^{230} \mathrm{Th}_{\mathrm{d}}$ and ${ }^{230} \mathrm{Th}_{\mathrm{d}-\mathrm{xs}}$

893 profiles do not differ significantly.

894

895

896

897 
Table ES2: Particulate thorium data (in situ pump filtration)

\begin{tabular}{|c|c|c|c|c|c|c|}
\hline Station & $\begin{array}{l}\text { Depth } \\
(\mathrm{m})\end{array}$ & $\begin{array}{l}\text { Volume }^{1} \\
\text { (L) }\end{array}$ & $\begin{array}{l}{ }^{232} \mathrm{Th}_{\mathrm{p}} \\
(\mathrm{pg} / \mathrm{kg})^{2}\end{array}$ & $\begin{array}{l}{ }^{230} \mathrm{Th}_{\mathrm{p}} \\
(\mathrm{pg} / \mathrm{kg})^{2}\end{array}$ & $\begin{array}{l}{ }^{230} \mathrm{Th}_{\mathrm{p}-\mathrm{xs}} \\
(\mathrm{pg} / \mathrm{kg})^{2}\end{array}$ & $\begin{array}{l}{ }^{230} \mathrm{Th}_{\mathrm{p}-\mathrm{xs}} \\
\text { particulate fraction }\end{array}$ \\
\hline \multicolumn{7}{|l|}{ S1 } \\
\hline & 30 & 346 & $7.0 \pm 0.1$ & $0.076 \pm 0.002$ & $0.045 \pm 0.003$ & $4 \%$ \\
\hline & 199 & 803 & $18.8 \pm 0.3$ & $0.209 \pm 0.004$ & $0.128 \pm 0.004$ & $6 \%$ \\
\hline & 1242 & 997 & $32.3 \pm 0.7$ & $1.45 \pm 0.03$ & $1.31 \pm 0.03$ & $18 \%$ \\
\hline & 2687 & 142 & $37.8 \pm 0.5$ & $1.309 \pm 0.003$ & $1.144 \pm 0.004$ & $8 \%$ \\
\hline & 2732 & 1202 & $17.3 \pm 0.5$ & $1.8 \pm 0.4$ & $1.7 \pm 0.4$ & $12 \%$ \\
\hline & 4628 & 610 & $371 \pm 10$ & $28.1 \pm 0.4$ & $26.5 \pm 0.4$ & $124 \%$ \\
\hline \multicolumn{7}{|l|}{ S2 } \\
\hline & 20 & 315 & $4.1 \pm 0.1$ & $0.148 \pm 0.004$ & $0.130 \pm 0.004$ & $18 \%$ \\
\hline & 257 & 814 & $8.9 \pm 0.1$ & $0.379 \pm 0.003$ & $0.340 \pm 0.003$ & $12 \%$ \\
\hline & 601 & 961 & $5.4 \pm 0.1$ & $0.492 \pm 0.004$ & $0.469 \pm 0.004$ & $9 \%$ \\
\hline & 1426 & 1053 & $9.1 \pm 0.1$ & $1.462 \pm 0.009$ & $1.422 \pm 0.009$ & $16 \%$ \\
\hline & 1941 & 531 & $8.5 \pm 0.1$ & $0.752 \pm 0.005$ & $0.715 \pm 0.005$ & $5 \%$ \\
\hline & 2859 & 515 & $8.9 \pm 0.1$ & $1.63 \pm 0.01$ & $1.59 \pm 0.01$ & $11 \%$ \\
\hline & 3858 & 508 & $93.1 \pm 1.2$ & $8.51 \pm 0.07$ & $8.10 \pm 0.07$ & $48 \%$ \\
\hline \multicolumn{7}{|l|}{ S3 } \\
\hline & 40 & 99 & $7.1 \pm 0.1$ & $0.163 \pm 0.002$ & $0.133 \pm 0.002$ & $12 \%$ \\
\hline & 594 & 500 & $4.41 \pm 0.04$ & $0.686 \pm 0.002$ & $0.667 \pm 0.002$ & $13 \%$ \\
\hline & 1058 & 967 & $5.1 \pm 0.1$ & $1.045 \pm 0.003$ & $1.023 \pm 0.003$ & $12 \%$ \\
\hline & 1985 & 1128 & $5.5 \pm 0.1$ & $1.426 \pm 0.004$ & $1.402 \pm 0.004$ & $13 \%$ \\
\hline & 3025 & 218 & $7.7 \pm 0.1$ & $1.778 \pm 0.006$ & $1.745 \pm 0.006$ & $12 \%$ \\
\hline & 3024 & 552 & $8.0 \pm 0.1$ & $1.838 \pm 0.005$ & $1.804 \pm 0.005$ & $12 \%$ \\
\hline & 4262 & 210 & $2.5 \pm 0.0$ & $0.344 \pm 0.002$ & $0.333 \pm 0.002$ & $4 \%$ \\
\hline \multicolumn{7}{|l|}{ S4 } \\
\hline & 59 & 381 & $0.076 \pm 0.001$ & $0.0202 \pm 0.0005$ & $0.0198 \pm 0.005$ & $2 \%$ \\
\hline & 169 & 702 & $1.48 \pm 0.02$ & $0.300 \pm 0.001$ & $0.294 \pm 0.001$ & $11 \%$ \\
\hline & 258 & 903 & $2.42 \pm 0.02$ & $0.467 \pm 0.001$ & $0.457 \pm 0.001$ & $9 \%$ \\
\hline & 743 & 984 & $2.23 \pm 0.02$ & $0.682 \pm 0.002$ & $0.672 \pm 0.002$ & $6 \%$ \\
\hline & 1119 & 1069 & $2.82 \pm 0.03$ & $0.630 \pm 0.002$ & $0.617 \pm 0.002$ & $4 \%$ \\
\hline & 1120 & 308 & $1.72 \pm 0.02$ & $0.368 \pm 0.002$ & $0.360 \pm 0.002$ & $2 \%$ \\
\hline & 1682 & 1018 & $2.23 \pm 0.02$ & $0.727 \pm 0.002$ & $0.717 \pm 0.002$ & $4 \%$ \\
\hline & 2273 & 938 & $6.07 \pm 0.06$ & $1.885 \pm 0.005$ & $1.858 \pm 0.005$ & $10 \%$ \\
\hline & 2469 & 493 & $6.25 \pm 0.06$ & $1.850 \pm 0.005$ & $1.823 \pm 0.005$ & $11 \%$ \\
\hline \multicolumn{7}{|l|}{ S5 } \\
\hline & 30 & 341 & $2.23 \pm 0.01$ & $0.706 \pm 0.005$ & $0.697 \pm 0.005$ & \\
\hline & 139 & 872 & $2.1 \pm 0.1$ & $0.261 \pm 0.002$ & $0.251 \pm 0.002$ & $3 \%$ \\
\hline & 248 & 927 & $2.5 \pm 0.1$ & $0.507 \pm 0.003$ & $0.496 \pm 0.003$ & $3 \%$ \\
\hline & 694 & 127 & $3.6 \pm 0.8$ & $0.555 \pm 0.009$ & $0.539 \pm 0.010$ & $2 \%$ \\
\hline & 1784 & 290 & $4.0 \pm 0.4$ & $0.714 \pm 0.006$ & $0.697 \pm 0.006$ & $2 \%$ \\
\hline & 2478 & 1066 & $8.5 \pm 0.1$ & $1.726 \pm 0.029$ & $1.69 \pm 0.03$ & $5 \%$ \\
\hline & 3172 & 905 & $11.6 \pm 0.2$ & $1.754 \pm 0.006$ & $1.703 \pm 0.006$ & $5 \%$ \\
\hline & 3840 & 715 & $26.1 \pm 0.3$ & $2.966 \pm 0.012$ & $2.852 \pm 0.012$ & $8 \%$ \\
\hline
\end{tabular}

$899{ }^{1}$ Fraction of the volume of filtered water used for Thorium analysis. ${ }^{2}$ Uncertainties are $2 \sigma_{\mathrm{n}}$ 900 (error on the mean).

901 
904 Table ES3: Total thorium isotopes recalculated on neutral density surfaces

\begin{tabular}{|l|c|l|c|c|c|c|c|}
\hline & Depth $(\mathrm{m})$ & $\begin{array}{l}\theta \\
\left({ }^{\circ} \mathrm{C}\right)\end{array}$ & Salinity & $\begin{array}{l}232 \\
(\mathrm{pg} / \mathrm{kg})\end{array}$ & error & ${ }^{230} \mathrm{Th}(\mathrm{fg} / \mathrm{kg})$ & error \\
\hline$\gamma^{\mathrm{n}}=27.865 \mathrm{~kg} / \mathrm{m}^{3}$ & & & & & & & \\
\hline $\mathrm{S} 1$ & -1550 & 2.732 & 34.695 & 10.67 & 0.15 & 72.4 & 1.5 \\
\hline S2 & -1631 & 2.564 & 34.667 & 11.51 & 0.12 & 36.3 & 1.3 \\
\hline S3 & -1227 & 2.44 & 34.644 & 10.07 & 0.13 & 25.1 & 2.9 \\
\hline S4 & -345 & 1.838 & 34.563 & 7.59 & 0.11 & 16.8 & 1.8 \\
\hline S5 & -98 & -0.665 & 34.348 & 8.52 & 0.11 & 21.8 & 0.1 \\
\hline & & & & & & & \\
\hline$\gamma^{\mathrm{n}}=28.094 \mathrm{~kg} / \mathrm{m}^{3}$ & & & & & & & \\
\hline S1 & 3073 & 1.86 & 34.827 & 15.1 & 0.2 & 60.7 & 1.5 \\
\hline S2 & 3082 & 1.849 & 34.823 & 17.3 & 0.8 & 52.9 & 0.2 \\
\hline S3 & 2440 & 1.722 & 34.756 & 15.2 & 0.2 & 32.1 & 1.3 \\
\hline S4 & 1205 & 1.322 & 34.726 & 15.9 & 0.2 & 29.3 & 1.3 \\
\hline intercal & -999.6 & 1.205 & 34.71 & 16.7 & 0.2 & 30.1 & 1.2 \\
\hline intercal & -999.6 & 1.205 & 34.71 & 16.7 & 0.2 & 30.2 & 1.3 \\
\hline S5 & 247 & 0.28616 & 34.619 & 16.1 & 0.2 & 31.9 & 1.6 \\
\hline
\end{tabular}

905 
906 Fig. ES1: comparison of particulate ${ }^{232} \mathrm{Th}$ collected by in situ pump and Niskin filtrations.
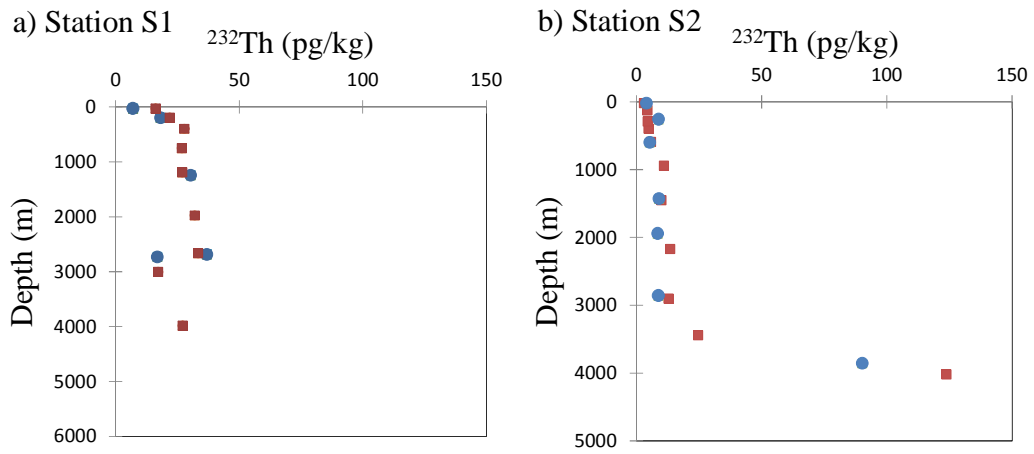

c) Station $\mathrm{S} 3 \quad{ }^{232} \mathrm{Th}(\mathrm{pg} / \mathrm{kg})$

d) Station $\mathrm{S} 4 \quad{ }^{232} \mathrm{Th}(\mathrm{pg} / \mathrm{kg})$
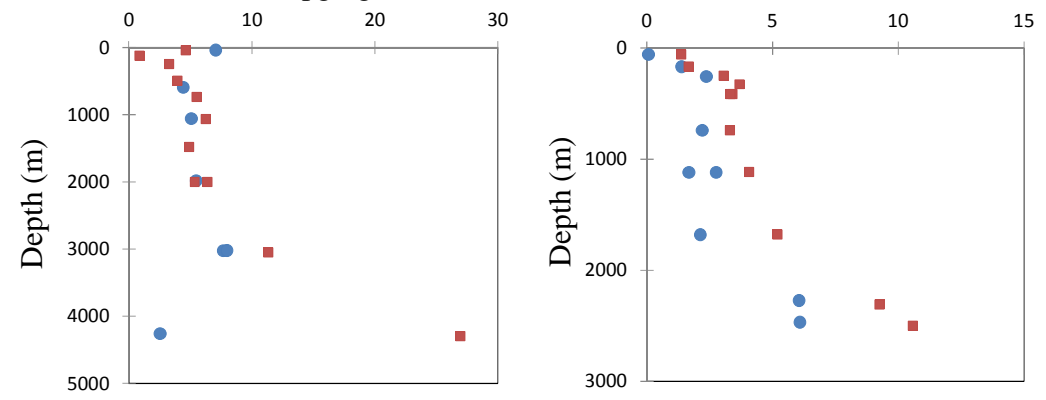

e) Station $\mathrm{S} 5 \quad{ }^{232} \mathrm{Th}(\mathrm{pg} / \mathrm{kg})$

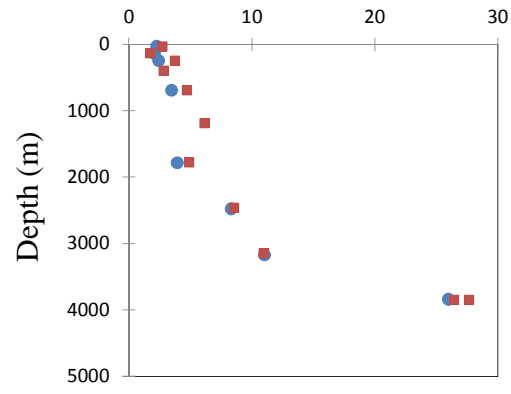

- Niskin filtration (Garcia-Solsona et al., 2014) - ISP filtration (this work) 
909 Figure ES2: Dissolved Th isotopes BGH sections. (a) ${ }^{232} \mathrm{Th}_{\mathrm{d} \cdot}$. (b): ${ }^{230} \mathrm{Th}_{\mathrm{d}}$. White curves: 910 neutral density surfaces.

911

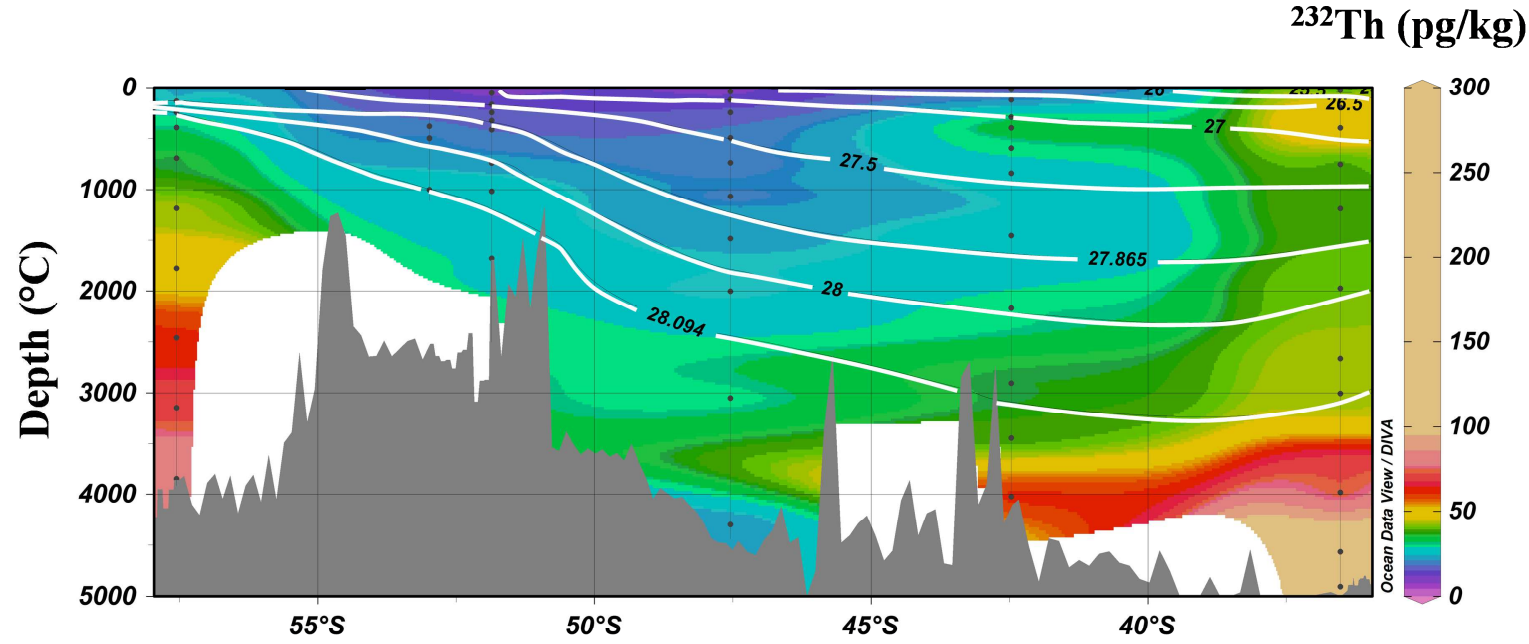

912

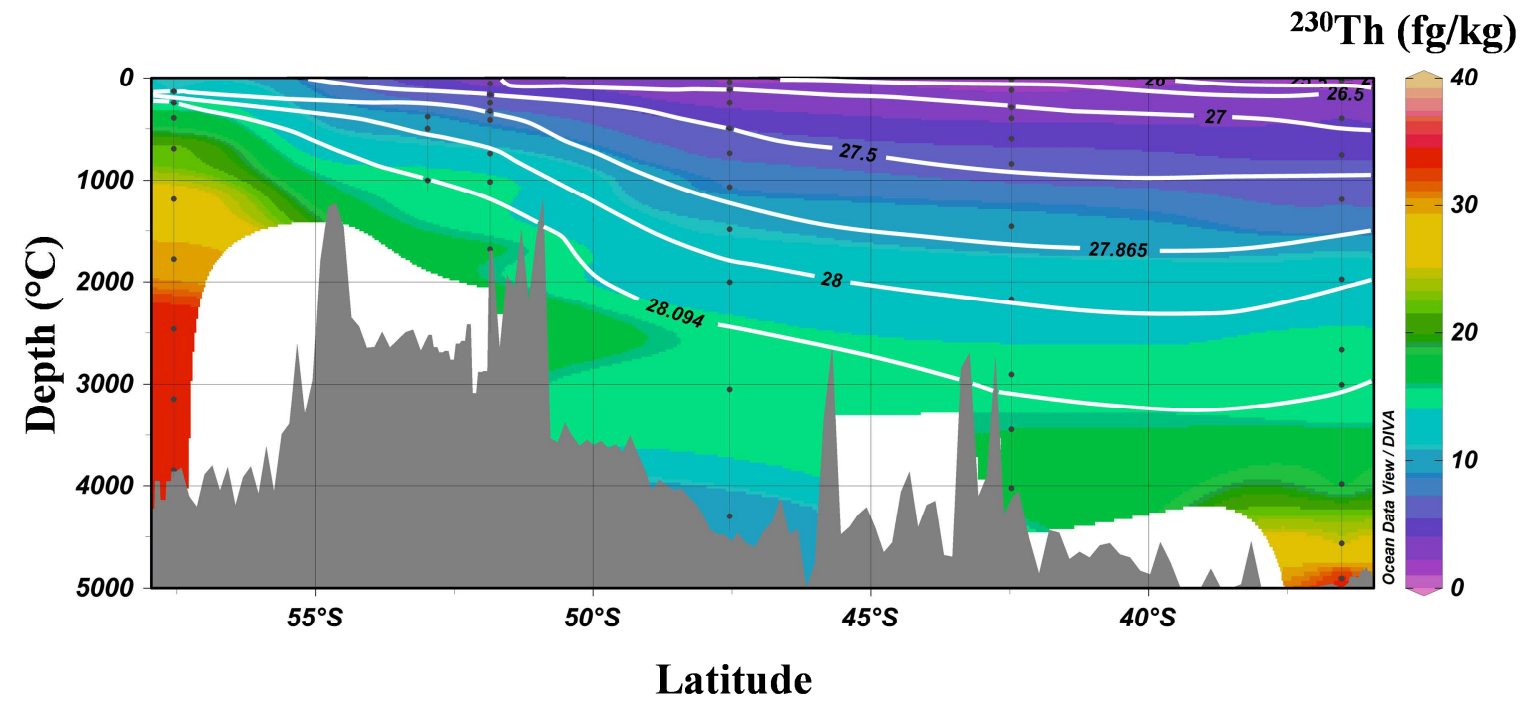

913

914

915

916

917

918

919 
921 Figure ES3: Dissolved Th comparison between 2 stations of the BGH and Zero-Drake 922 sections. ${ }^{232} \mathrm{Th}_{\mathrm{d}}$ and ${ }^{230} \mathrm{Th}_{\mathrm{d}}$ are plotted versus potential density anomaly in order to reduce 923 hydrographical variations between the 2 cruises.
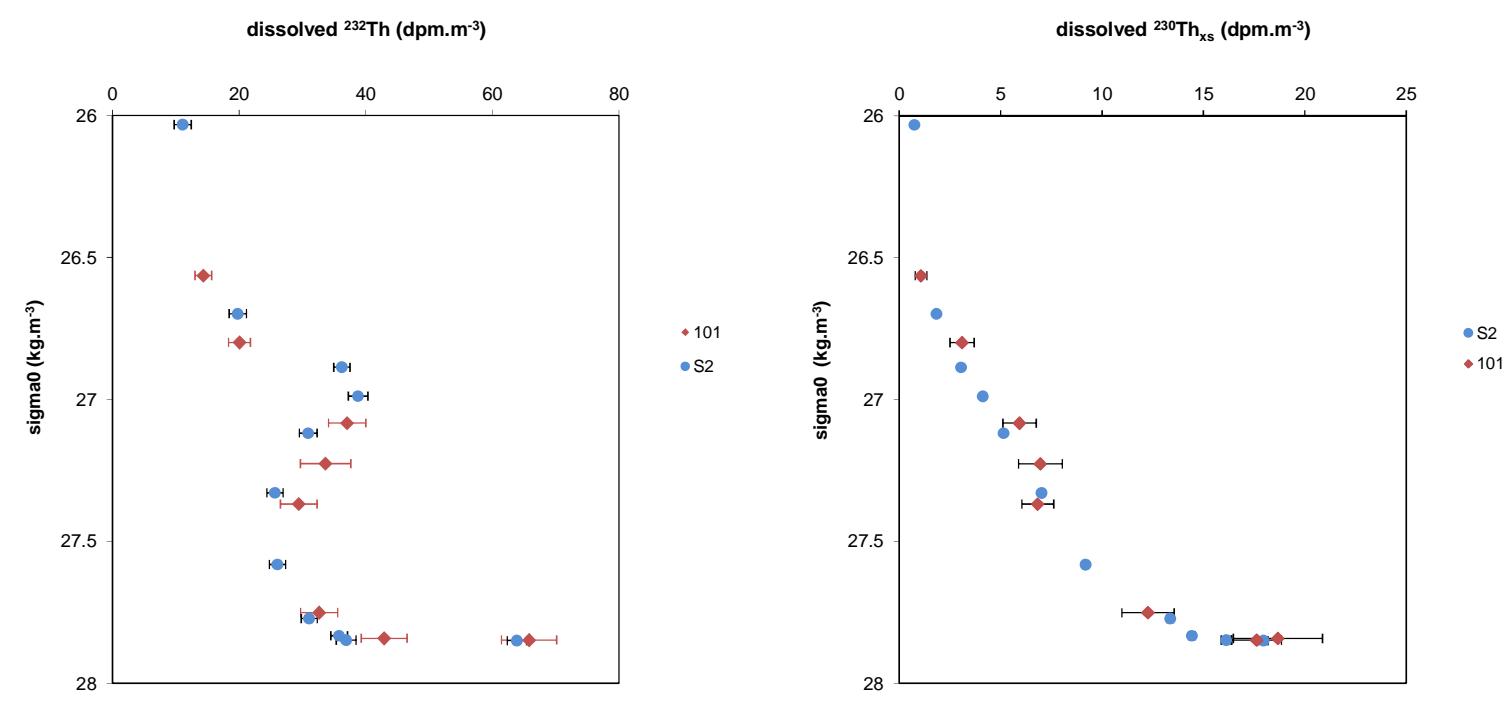

925

926
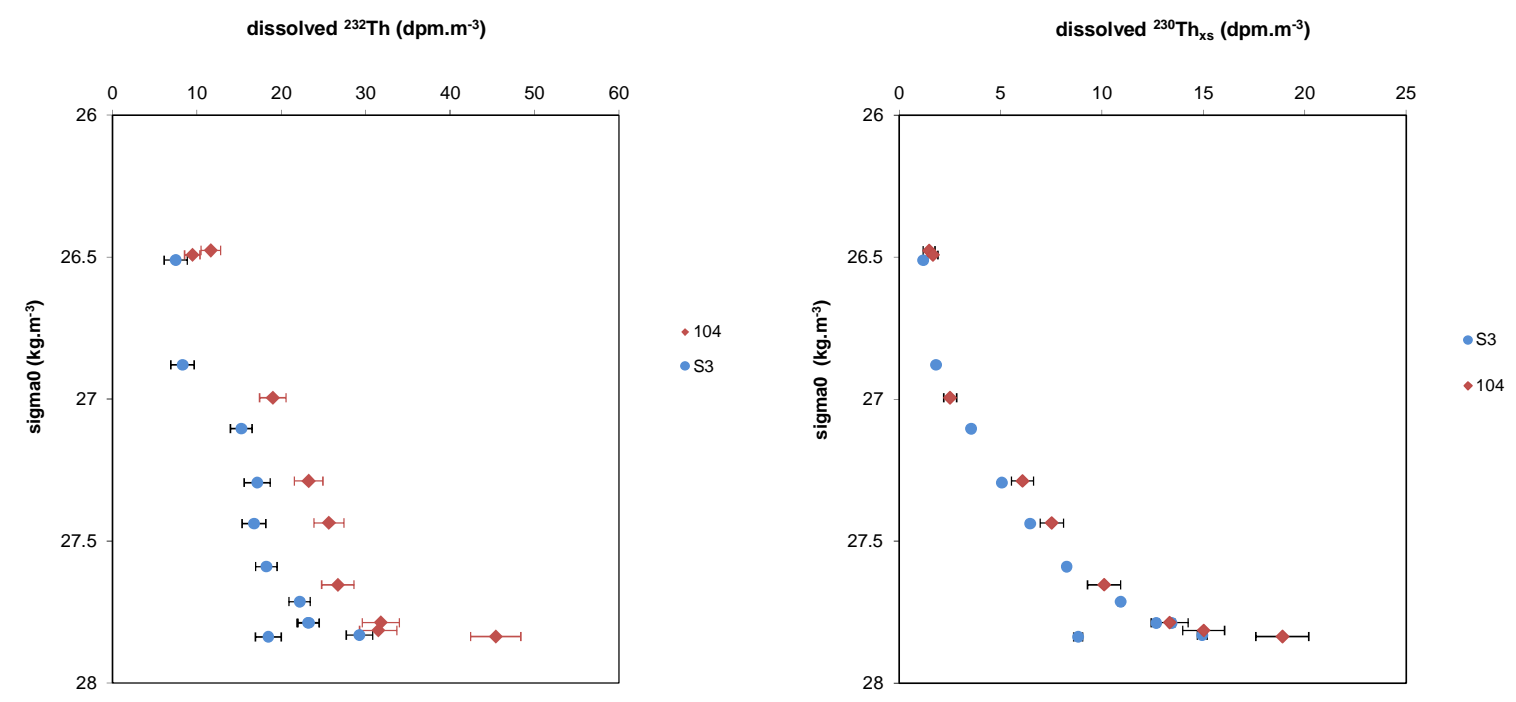